\title{
Fibrinogen and fibrin based micro and nano scaffolds incorporated with drugs, proteins, cells and genes for therapeutic biomedical applications
}

This article was published in the following Dove Press journal:

International Journal of Nanomedicine

25 September 2013

Number of times this article has been viewed

\section{Thanavel Rajangam \\ Seong Soo A An}

Department of Bionanotechnology, Gachon University, Seongnam-Si, Republic of Korea
Correspondence: Seong Soo A An Department of Bionanotechnology, Gachon University, San 65, BokjeongDong, Sujeong-Gu, Seongnam-Si, Gyeonggi-Do 46I-70I, Republic of Korea Tel +82317508755

Fax +82317508755

Email seongaan@gachon.ac.kr

\begin{abstract}
Over the past two decades, many types of natural and synthetic polymer-based micro- and nanocarriers, with exciting properties and applications, have been developed for application in various types of tissue regeneration, including bone, cartilage, nerve, blood vessels, and skin. The development of suitable polymers scaffold designs to aid the repair of specific cell types have created diverse and important potentials in tissue restoration. Fibrinogen (Fbg)- and fibrin (Fbn)-based micro- and nanostructures can provide suitable natural matrix environments. Since these primary materials are abundantly available in blood as the main coagulation proteins, they can easily interact with damaged tissues and cells through native biochemical interactions. Fbg- and Fbn-based micro and nanostructures can also be consecutively furnished/ or encapsulated and specifically delivered, with multiple growth factors, proteins, and stem cells, in structures designed to aid in specific phases of the tissue regeneration process. The present review has been carried out to demonstrate the progress made with micro and nanoscaffold applications and features a number of applications of Fbg- and Fbn-based carriers in the field of biomaterials, including the delivery of drugs, active biomolecules, cells, and genes, that have been effectively used in tissue engineering and regenerative medicine.
\end{abstract}

Keywords: biomaterial, polymer composite, cross-linking, growth factor, drug delivery, controlled release, tissue regeneration

\section{Introduction}

Tissue engineering is a multidisciplinary area that encompasses biology, chemical engineering, material science, and chemistry. Existing techniques have the potential to create specific tissues and organs in vitro and in vivo. For fabrication of biomimetic scaffolds, a range of synthetic and protein-based polymer scaffolds, such as collagen, gelatin, elastin, proteoglycan, hyaluronan, laminin, silk fibroin, soybean, fibrinogen (Fbg), and fibrin (Fbn) have been widely used. Among these polymers, Fbg- and Fbn-based scaffolds have been widely used to construct functional substitutes (tissues and organs), which may provide a permanent solution to damaged tissue and organs without need for additional therapies, due to their nonimmunogenicity (autograft) and their ability to mimic the organization of native tissue structures. Fbg is a $340 \mathrm{kDa}$ blood protein involved in blood coagulation and platelet aggregation (thrombogenesis). When Fbg and thrombin solutions are mixed together in the presence of $\mathrm{Ca}^{2+}$ forms Fbn through polymerization, it can be digested by the proteolytic enzyme (plasmin) through fibrinolysis. ${ }^{1}$ Similar to collagen, Fbg and Fbn scaffolds can attain a high cell seeding efficiency and uniform cell distribution and can then proliferate, migrate, and differentiate into specific tissues/organs by secreting extracellular matrix (ECM) 
(which is involved in the generation of tissue). ${ }^{2} \mathrm{Fbg}$ has major healing advantages, as it provides a favorable surface for cellular attachment and proliferation - a three-dimensional (3-D) fibrous structural support and nanotextured surfaces, which consist of a fibrous network for cell signaling, and cell-matrix and cell-cell interactions. ${ }^{3}$ Especially in tissue engineering, Fbg- and Fbn-based scaffolds induce ECM production that renders support to connective tissues, such as cartilage, ligament, bones, tendons, nerves, blood vessels, and skin. ${ }^{4-8}$

Fbg and Fbn can be easily formulated into diverse structural scaffolds because of their micro- and nanocharacteristic; micro/nanoporous scaffolds, such as microspheres, ${ }^{9}$ microfibers, ${ }^{10}$ microtubes, ${ }^{11}$ nanoparticles, ${ }^{12}$ nanofibers, ${ }^{13}$ and hydrogels, ${ }^{14}$ have been formulated for diverse tissue engineering applications. In a vast range of severe pathological conditions, such as chronic wounds, diabetic ulcer, and ischemic heart disease, the rate of reepithelialization and neovascularization can predict the therapeutic approach towards perfusion and healing of damaged tissue. ${ }^{15-17}$ Since Fbg and Fbn scaffolds are considered to be natural provisional ECM, they also play a significant role in the early stages of hemostasis and wound repair, in addition to blood clotting. Furthermore, Fbg contains two Arginine-Glycine-Aspartate (RGD) integrin-binding sites, which usually bind endothelial and fibroblast cells. ${ }^{18}$ Fbg also has a high affinity towards biomolecules, such as vascular endothelial growth factor (VEGF), fibroblast growth factor (FGF), and many other tissue-inductive cytokines. ${ }^{5,19}$

Current 3-D scaffolds may incorporate different structural features, such as micro/nanoporous matrices or composites, micro/nanofibers with porous characteristics, micro/nanospheres or particles, and micro/nanofiber composites within porous scaffold. Micro/nanospheres or particles within a porous scaffold (shown in Figure 1) have attracted special interest for potential tissue engineering and regenerative applications. In many cases, growth factors/cells/deoxyribonucleic acid (DNA) can be integrated into Fbg and Fbn scaffolds by bulk encapsulation, specific/nonspecific physical adsorption, surface fictionalization, or by the use of protein or cell adhesive binders, as illustrated in Figure 2. Micro/nanocarriers or composites encapsulated with growth factors and/or drugs can be delivered to a targeted site to induce/mimic ECM productions, where tissues need to be regenerated. For specific tissue engineering applications, cell proliferation and differentiation towards specific phenotype is very favorable. To attain this successfully, in situ and in vivo sustained delivery with various drug and growth factors within Fbg and Fbn micro/nano scaffolds have been studied..$^{20,21}$ Further, these scaffolds loaded with growth factors, such as VEGF, ${ }^{22}$ epidermal growth factor (EGF), ${ }^{23}$ nerve growth factor (NGF), ${ }^{24}$ and bone morphogenic protein $(\mathrm{BMP})^{25}$ were shown to stimulate blood vessel, skin, nerve and bone growth, respectively. Such scaffolds have also been extensively studied with various tissue inductive growth factors, such as transforming growth factor (TGF), ${ }^{26}$ FGF, ${ }^{27}$ fibronectin (FN), ${ }^{28}$ keratinocytes, ${ }^{29}$ etc, for the growth of various tissues. Furthermore, the controlled release of these growth factors from Fbg and Fbn scaffolds provides a number of vital advantages, as growth factors transported into the target environment may locally govern multiple processes of the cell, such as attachment, proliferation, differentiation, and morphogenesis.

The development of techniques for the regeneration of different tissues (skin, nerve, vascular, and cartilage) is not only based on the delivery of corresponding growth factors, but is also dependent upon the polymer carrier and types of cell interactions. For example, alginate, ${ }^{30}$ dextran, ${ }^{31}$ hyaluronan, ${ }^{32}$ heparin, ${ }^{32}$ polyvinyl alcohol, ${ }^{33}$ and poly lactic-co-glycolic acid $(\mathrm{PLGA})^{34}$ scaffolds have all been used for vascular repair/ regeneration, wound healing, and other tissue engineering applications. However, these polymeric materials have their own disadvantages, such as rapid degradation, denaturation of growth factors due to irreversible complexation, lack of cell proliferation, and production of acidic environments in the ischemic wound area, which could reduce protein moiety functions, as well as cause potential immune responses and acute inflammation. ${ }^{35}$

The material used for fabricating an ideal scaffold must meet a number of basic criteria, such as providing an appropriate environment for enabling cellular function, cell migration, proliferation, and differentiation, and also must allow for tissue regeneration/development. Most importantly, the scaffold should not evoke any immune reactions, while providing a feasible model for cellular interaction/proliferation. Moreover, scaffolds should mimic both the fibrallar form and complex biochemical role of native ECM. ${ }^{3}$ In this review, we highlight the methods for fabricating Fbg- and Fbn-based micro/nanocarriers, including the use of hydrogel and Fbg/Fbn blended natural and synthetic matrices that are used for biomedical applications like drug release, wound dressing, and in tissue engineering and cancer therapy.

Herein we present a detailed discussion of the theory behind Fbg and Fbn use and of their use as micro/ nanoscaffolds, integrated with biomolecules and cells, in tissue engineering applications; their applications for 


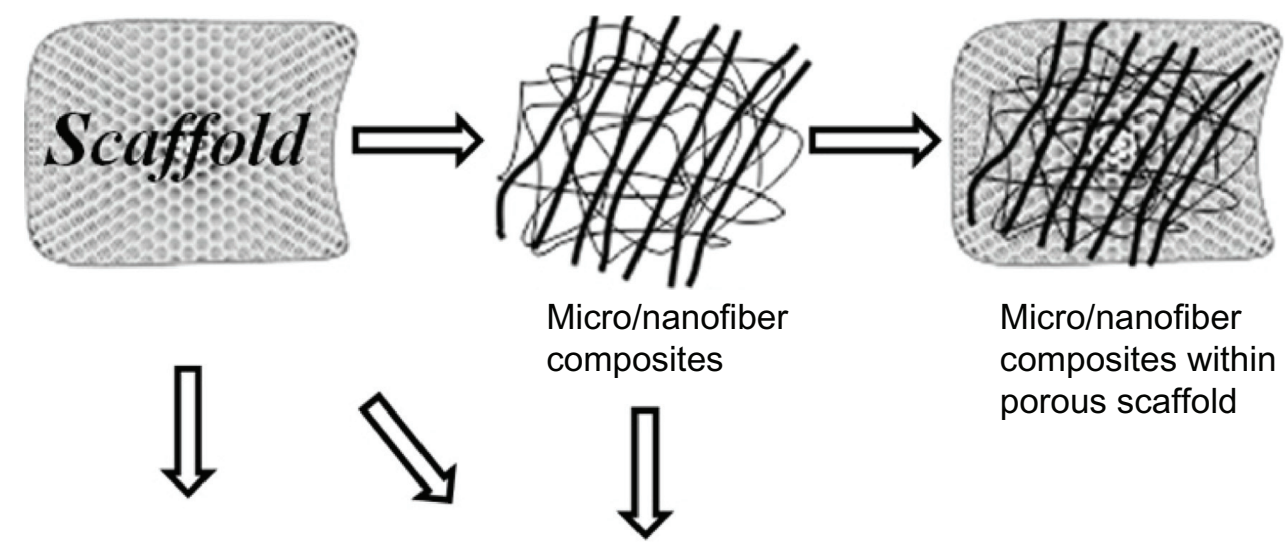

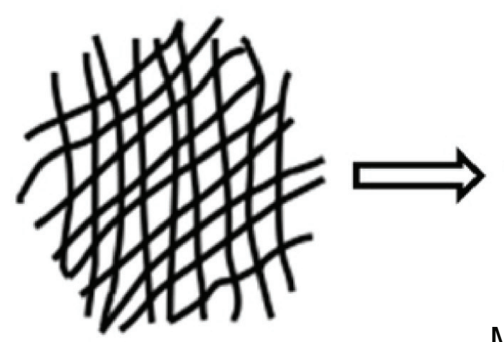

Microfibers
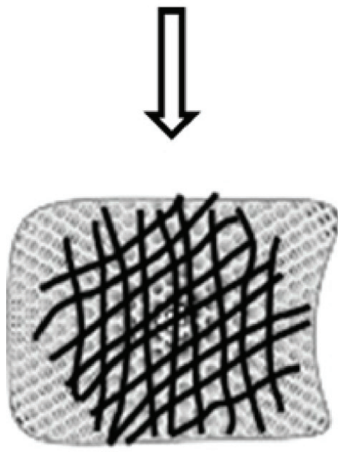

Microfibers within porous scaffold

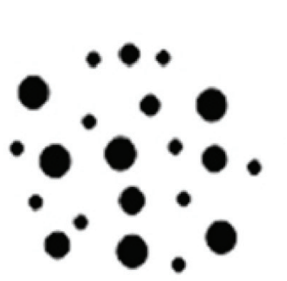

Micro/nanosphere or particle composites
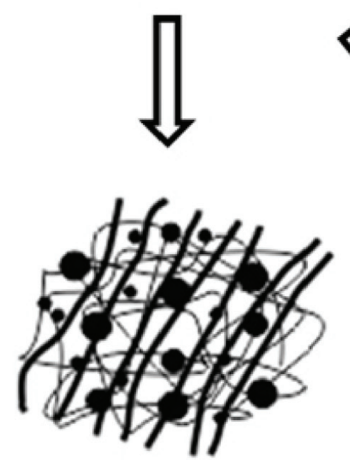

Microfiber and micro/ nanosphere or particles composites

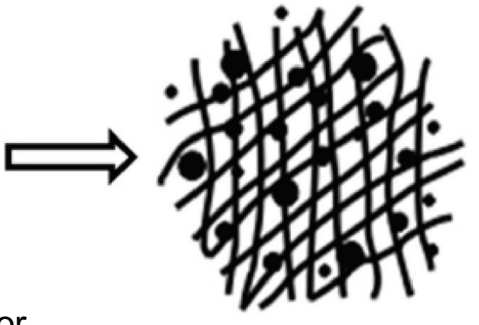

Micro/nanospheres or particles within microfiber scaffold
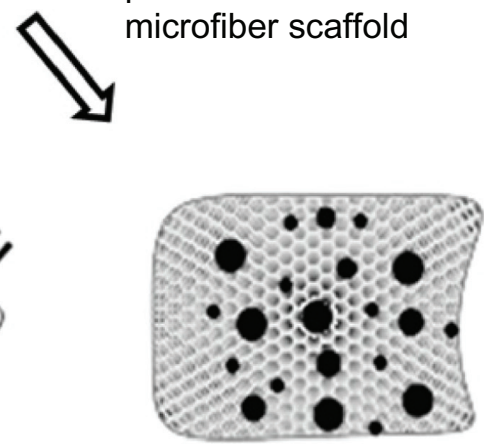

Micro/nanosphere or particles within porous scaffold

Figure I Polymer composite scaffolds prepared with incorporation of micro/nanospheres or micro/nanofibers.

specific tissues, such as vascular maladies, bone and cartilage, skin constructs, and nerve conduits, will also be discussed in detail.

\section{Preparation of Fbg- and Fbn-based carriers and their biomedical applications}

Different fabrication methods have been used to prepare a diversity of Fbg and Fbn scaffolds, such as microspheres, microbeads, microfibers, nanoparticles, nanofibers, and hydrogels. These scaffolds have been designed and optimized with desired properties, such as size, shape, and porosity with interconnected structures that are suitable for culturing preferred types of cells. Most of the scaffolds used in tissue engineering applications have either a uniform size or shape, and random pore structures with interconnected networks. These pore structures can aid cell attachments, cell-matrix interactions, and nutrient/waste metabolite transport. For most biological applications, such pore structures/surfaces are required for the sustained release of loaded drug/biomolecules, to maintain bioavailability or specific tissue regeneration. In many cases, Fbg and Fbn scaffolds have an amorphous nature, which can improve the drug-loading efficacy and mechanical performances of the scaffolds. The following sections describe the various types of micro- and nanocarrier preparations and their applications. 


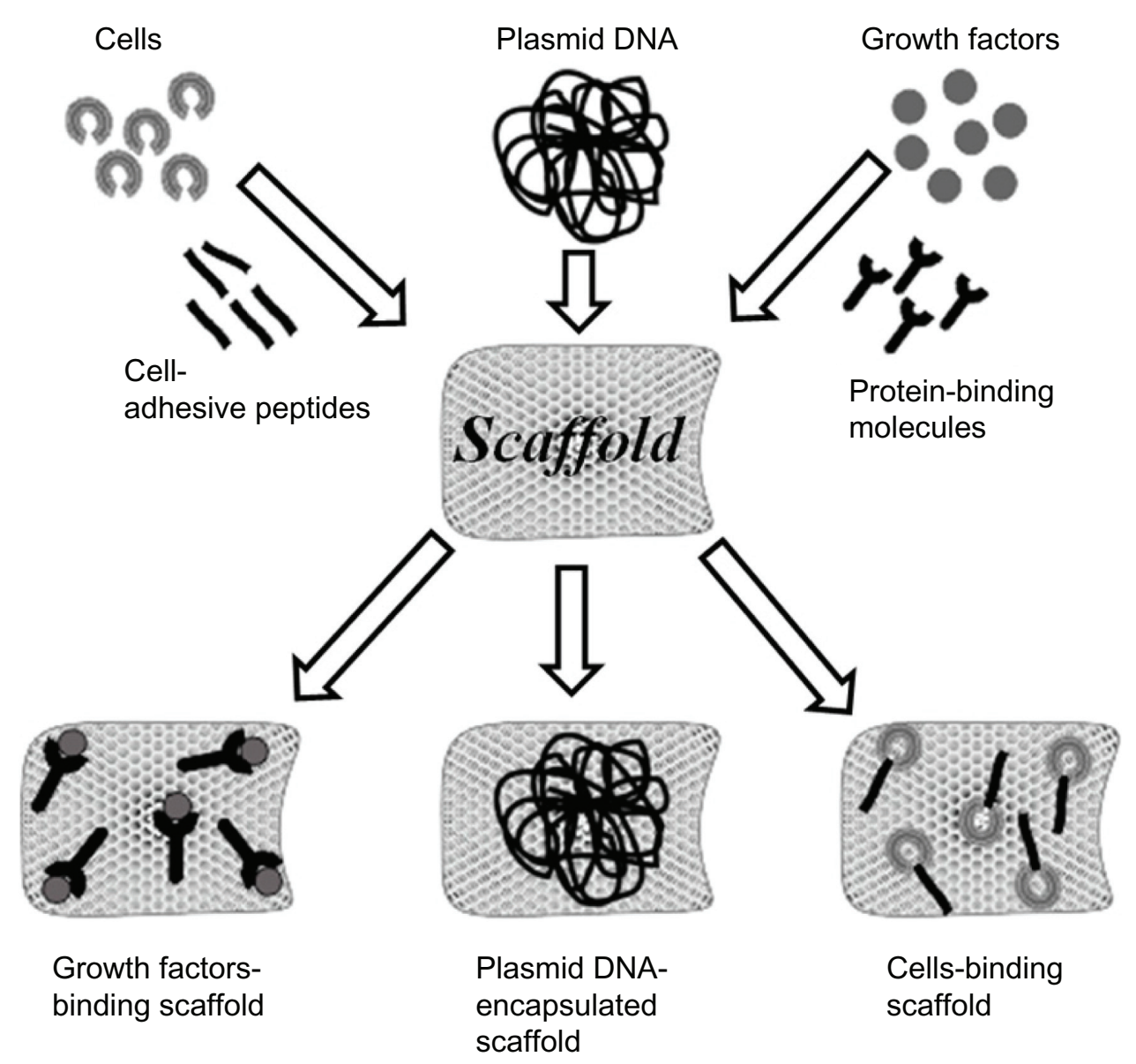

Figure 2 Incorporation of cells/DNA/growth factors into the scaffold matrix. Abbreviation: DNA, deoxyribonucleic acid.

\section{Fbg and Fbn microspheres/beads and nanoparticles as scaffolds}

Fbg- and Fbn-based microspheres/beads and nanoparticles are widely used in a diverse range of pharmaceutical and biomedical applications, such as drug delivery, protein/ peptide delivery, chemotherapy, and wound dressings and hemostatic bandages. Miyazaki et al were the first to report the fabrication of Fbg microspheres using a water and oil (W/O) emulsification method. ${ }^{36}$ The prepared microspheres were then applied as a novel drug carrier for anticancer drug delivery. A few years later, Fbn microbeads were prepared by mixing both Fbg and coagulation factors (thrombin and calcium ions); additionally, glutaraldehyde was added to this system to minimize the coagulation of Fbn beads. The beads were then successfully used for various macromolecular delivery systems (insulin, lysozyme, ovalbumin, and bovine serum albumin). ${ }^{37}$ In another study, Fbg-coated albumin microcapsules were administered via intravenous administration, to reduce bleeding in animals and to reduce bleeding time in surgical wounds in muscles and abdominal skin. ${ }^{38}$
Generally, microspheres contain pore structures with interconnected networks, which assist in cell infiltration and in cell-matrix interaction. Recently, our group prepared Fbg microspheres $(100-150 \mu \mathrm{m})$ with pore structures using a W/O emulsification solvent extraction method, for use in various biomedical applications. These are shown in Figure 3. Using this method, the spheres size and uniformity can be controlled with the Fbg solution concentrations (wt\%), flow rate, and the stirrer rotating speed. ${ }^{9}$ Using the same method, Fbg nanospheres were also developed by further optimization of the above parameters, as shown in Figure 4. However, since the data is not yet published, the preparation method is not described here. Table 1 lists methods for fabricating Fbg and Fbn micro- and nanoscale scaffolds, which have been used for various pharmaceutical applications.

\section{Fbg and Fbn micro/nanofiber as scaffolds}

In tissue engineering, 3-D fibrous scaffolds with a large surface area can generally support high cell density and long-term cultures, and provide a better link between single 

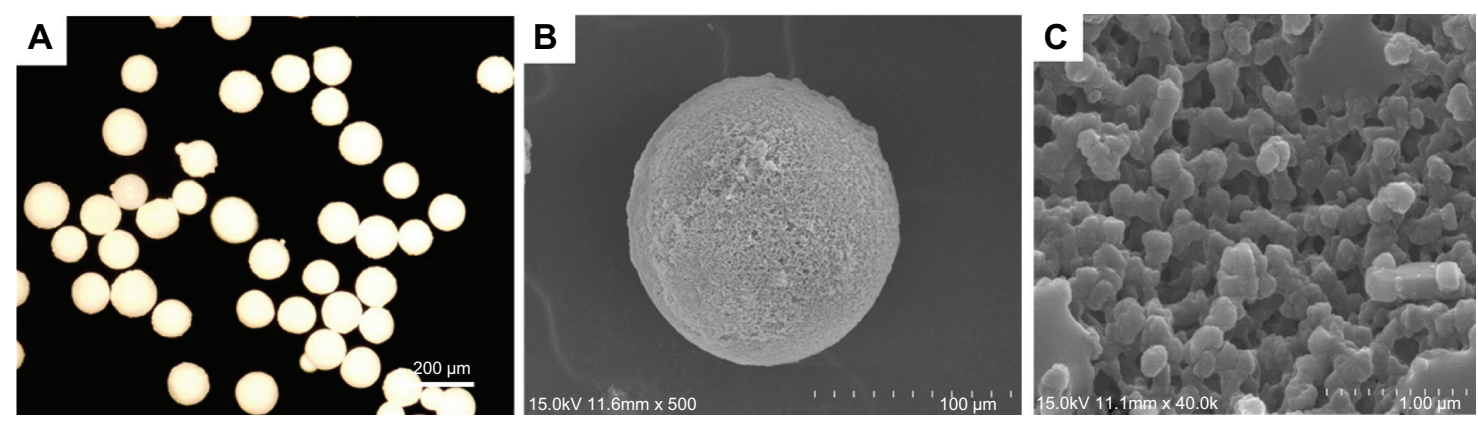

Figure 3 Microscopic images of Fbg microspheres.

Notes: (A) Light microscope image shows the microsphere sphericity and approximately uniform sizes, between I00-150 $\mu$ m; (B) SEM image further confirmed sphericity; (C) Magnified image of (B), reveals the porous structures. Copyright (C) 20I I, Springer Science+Business Media. Reproduced with permission from Rajangam T, Paik HJ, An SSA. Development of fibrinogen microspheres as a biodegradable carrier for tissue engineering. BioChip J. 201 I;5(2): 175-183. ${ }^{9}$

Abbreviations: Fbg, fibrinogen; SEM, scanning electron microscope.

cells and organs than do conventional 2-D cultures. There is a list of methods available for the fabrication of polymer micro and nanofibrous scaffolds with 3-D structures: electrospinning, self-assembly, phase separation, 3-D printing, and fiber bonding. Each method has its own advantages and disadvantages, although the choice of method is also based on the polymer characteristics.

To fabricate 3-D Fbg fibers, electrospinning methods have been preferred due to their practicality and flexibility. Wnek et al were the first to report the fabrication of Fbg nanofiber using an electrospinning method: First, an Fbg suspension was prepared with 1,1,1,3,3,3-hexafluoro2-propanol (HFP) and minimal essential medium (9:1); the mixture was left overnight and then, the homogenous solution was electrospun with a high-voltage supply $(22 \mathrm{kV}) \cdot{ }^{13}$ The electrospun nanofiber showed an average size of 80-700 $\mathrm{nm}$ diameter, and the 3-D fiber was effectively used as a wound dressing and hemostatic bandage. McManus et al also prepared a Fbg nanofiber, using the same method and suspending agents, and in order to further evaluate the fiber surface porosity, nanofibers with two different Fbg concentrations were fabricated..$^{43}$ The nanofiber produced with the lower Fbg concentration $(110 \mathrm{mg} / \mathrm{mL})$ showed a higher average porosity value (59\%) than did the highconcentration Fbg (130 mg/mL) nanofiber (54\%), due to the greater degree of solvent evaporation. However, both spun fibrous mats could act as a biomimetic scaffold and were deemed to be especially appropriate for use as wound dressings. The same research group, in other studies, assessed the cellular interaction and scaffold remodeling with $\mathrm{Fbg}$ nanofibers, using neonatal rat cardiac fibroblast cells; in these, the postculture mat histology evidenced that the Fbg scaffold was easily remodeled by the deposition of native collagen. ${ }^{44}$ Electrospinning-prepared Fbg nanofiber was also used to evaluate in vitro cell migration on the scaffold surface. ${ }^{45}$ Carlisle et al analyzed the mechanical properties of a single electrospun Fbg nanofiber, using a combined atomic force/fluorescence microscopic technique, and the result indicated that Fbg nanofiber had a high extensibility. ${ }^{46}$ High-extensibility fiber scaffolds have been found to be more widely applicable for in vitro and in vivo tissue engineering due to their flexibility. Electrospun Fbg nanofibers that
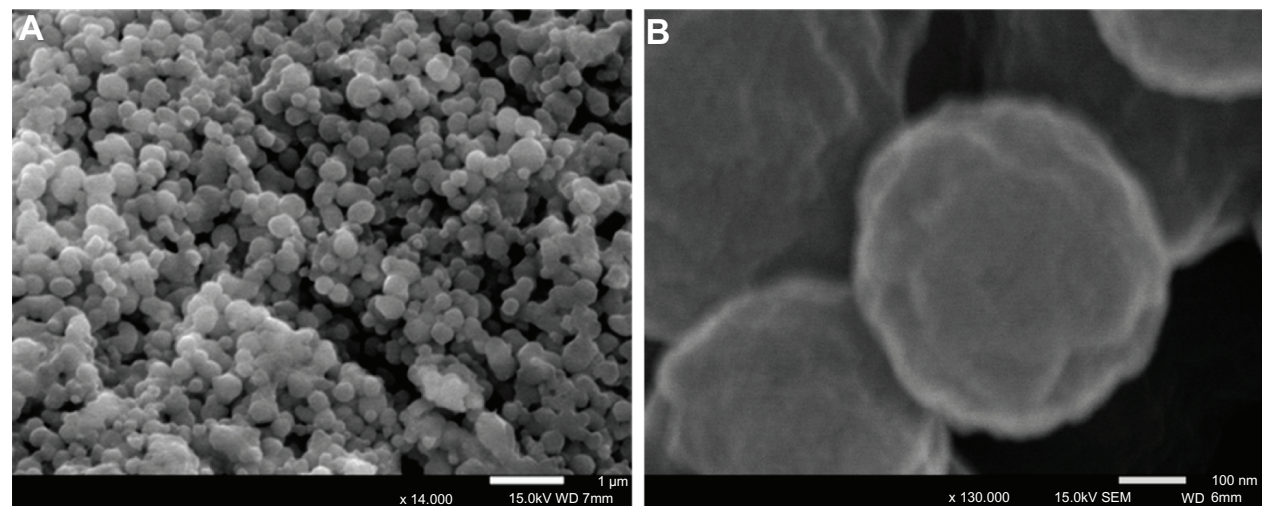

Figure 4 SEM images of Fbg nanospheres shown at different magnifications (image "A $\times 14,000$ " and image "B $\times 130,00$ " magnification). Abbreviations: Fbg, fibrinogen; SEM, scanning electron microscope. 
Table I Microcarrier fabrication methods using Fbg and Fbn and their biomedical applications

\begin{tabular}{|c|c|c|c|}
\hline $\begin{array}{l}\text { Matrix } \\
\text { structures }\end{array}$ & $\begin{array}{l}\text { Preparation } \\
\text { methods }\end{array}$ & Applications & Ref \\
\hline $\begin{array}{l}\text { Fbg } \\
\text { microspheres }\end{array}$ & $\begin{array}{l}\text { Emulsification } \\
\text { solvent extraction }\end{array}$ & $\begin{array}{l}\text { Carrier for injectable } \\
\text { (5-fluorouracil) } \\
\text { anticancer therapy }\end{array}$ & 36 \\
\hline $\begin{array}{l}\text { Fbg } \\
\text { microspheres }\end{array}$ & $\begin{array}{l}\text { Emulsification } \\
\text { solvent extraction }\end{array}$ & $\begin{array}{l}\text { Carrier for injectable } \\
\text { (Adriamycin) anticancer } \\
\text { therapy }\end{array}$ & 39 \\
\hline $\begin{array}{l}\text { Fbn } \\
\text { microbeads }\end{array}$ & $\begin{array}{l}\text { Preheated oil } \\
\text { emulsion }\end{array}$ & Wound healing & 40 \\
\hline $\begin{array}{l}\text { Fbn } \\
\text { microbeads }\end{array}$ & $\begin{array}{l}\text { Moderate heat } \\
\text { condensation }\end{array}$ & $\begin{array}{l}\text { Stem cell carriers for } \\
\text { wound tissue regeneration }\end{array}$ & 8 \\
\hline $\begin{array}{l}\text { Fbn } \\
\text { microbeads }\end{array}$ & Emulsion & $\begin{array}{l}\text { Deliver macromolecules } \\
\text { and protein drugs }\end{array}$ & 41 \\
\hline $\begin{array}{l}\text { Fbg } \\
\text { nanoparticles }\end{array}$ & $\begin{array}{l}\text { Two-step } \\
\text { coacervation } \\
\text { technique }\end{array}$ & Cancer drug delivery & 42 \\
\hline
\end{tabular}

Abbreviations: Fbg, fibrinogen; Fbn, fibrin.

interacted with human bladder smooth muscle cells showed rapid proliferation and demodulation as well as relatively slow rates of degradation. ${ }^{47}$ In other studies, McManus et al reported the fabrication of Fbg-polydioxanone composite nanofibers with high mechanical strength for potential in situ urologic tissue development. ${ }^{48}$ In electrospinning, the fiber size can be controlled by controlling the voltage and the distance between the needle and the collecting plate.

Usually, 3-D fiber scaffolds of the micron size range have greater mechanical strength, a property that could enhance cell adhesion, proliferation, and ease of handling during in vitro postmodification or implantation over the nanofiber scaffolds. On the other hand, they lack nanotextured topographical features, which are needed for the scaffold to mimic like native ECM. ${ }^{49}$ Further, successes in directing cells towards certain cellular morphologies, functions, and differentiations have been studied with diverse types of nanofibers. ${ }^{49,50}$ Recent studies of tissue engineering have paid great attention to combining these two scaffold features towards the development of ideal scaffold fabrication. Recently, we developed nanofiber-aligned Fbg microfibers, which showed a higher rate of biomolecule encapsulation and proliferation than other highly porous and less pores Fbg microfibers. ${ }^{51}$ The structurally different Fbg microfibers were prepared by a simple tubular gel-solvent extraction method without high-power voltage or high pressure (Figure 5). Here, the Fbg suspension was prepared using aqueous phosphate-buffered saline. In our laboratory, we also prepared a highly porous Fbg sheet composed of micro- and nanostructures, using a freeze-drying method (Figure 6). However, since the data has not yet been published, the preparation method has not been described.

\section{Fbg and Fbn hydrogel as scaffolds}

Fbn hydrogels have been most widely used as scaffolds for the reconstruction of different tissue and have been used as a biological adhesive for various procedures, such as abdominal, vascular oral, thoracic, and endoscopic surgeries. ${ }^{52-54}$ Mostly, Fbn hydrogels have been prepared by mixing Fbg with thrombin solution in the presence of $\mathrm{Ca}^{2+}$. Thrombin can cleave peptide fragments from soluble Fbg, thereby yielding insoluble Fbn peptides that aggregate to form fibril hydrogel networks. ${ }^{14}$ The characteristics of the Fbn fibril network formation were mainly based on the thrombin concentrations. For example, an increased thrombin concentration was found to be associated with shorter gelation time, the formation of more fiber bundles with thinner fibers size, and with low porosity. On other hand, lower thrombin concentrations were found to have longer gelation time, fewer fiber bundles with thicker fibers size, and more porous structures. ${ }^{55-57}$ In many cases, the constructed hydrogels have lacked mechanical strength, and to overcome this problem, the hydrogels were blended with biocompatible, biodegradable synthetic polymers ${ }^{58}$ or were seeded with cells either by static or dynamic methods. ${ }^{59}$

Rowe et al proposed a tubular, 3-D smooth muscle cell-seeded Fbn hydrogel construct for vascular tissue engineering. Here, the cells were directly mixed with the Fbg solution, were injected into an annular mold, and were then polymerized by the addition of thrombin. Further evaluation in this study concluded that the concentration of thrombin plays major roles in the outcome, influencing mechanical properties, fibril morphology, and cellular behavior. ${ }^{14}$ In another study, Almany and Seliktar developed unique Fbgbased biosynthetic hybrid hydrogels. The Fbg fragments were cross-linked with a dysfunctional polyethylene glycol (PEG) side chain to make a PEG-Fbg hybrid hydrogel. The developed hydrogel had both good cell adhesion and mechanical properties because Fbg offers cellular adhesive domains, while PEG provides mechanical and structural properties. ${ }^{60}$ PLGA microsphere-immobilized Fbn hydrogel provides an improved elastic modulus for chondrocyte proliferation and ECM production. ${ }^{61}$ Fbn hydrogel containing BMP-2 loaded poly(l-lysine) nanoparticles and human mesenchymal stem cells (MSCs) evidenced that the Fbn constructs significantly improved the proliferation of human MSCs in bone regeneration. The study also suggested that this might be one of the most promising methods for enhancing bone 

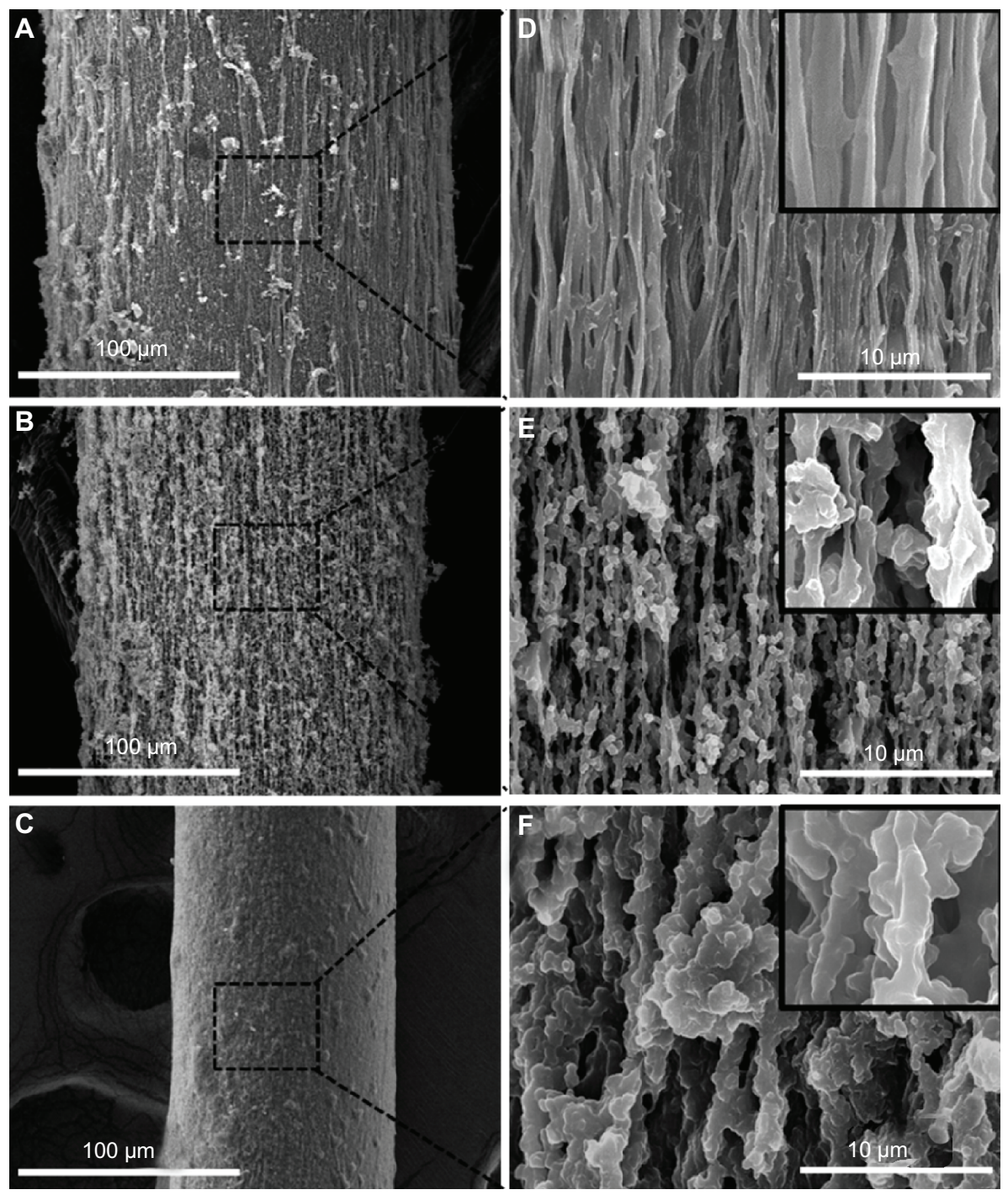

Figure 5 SEM images of Fbg microfibers fabricated from three different concentrations of Fbg.

Notes: Decreasing fiber diameter was observed with decreasing Fbg concentration. Images (A-C) show $200 \mu \mathrm{m}, 150 \mu \mathrm{m}$, and $75 \mu \mathrm{m}$ fibers, respectively, which were made from 15, 10, and 5 wt\% Fbg, respectively. Images (D-F) represent highly aligned nanostructures, highly interporous fibers with aggregated structures, and less porous fibers with unaligned structure, respectively, and are the same as the lower magnification images in (A-C), respectively (inlet images scale bar is I $\mu \mathrm{m}$ ). Copyright $\odot 2012$, Dove Medical Press Ltd. Reproduced with permission from Rajangam T, An SS. Improved fibronectin-immobilized fibrinogen microthreads for the attachment and proliferation of fibroblasts. Int J Nanomedicine.2013;8: 1037-1049..$^{5}$

Abbreviations: Fbg, fibrinogen; SEM, scanning electron microscope.
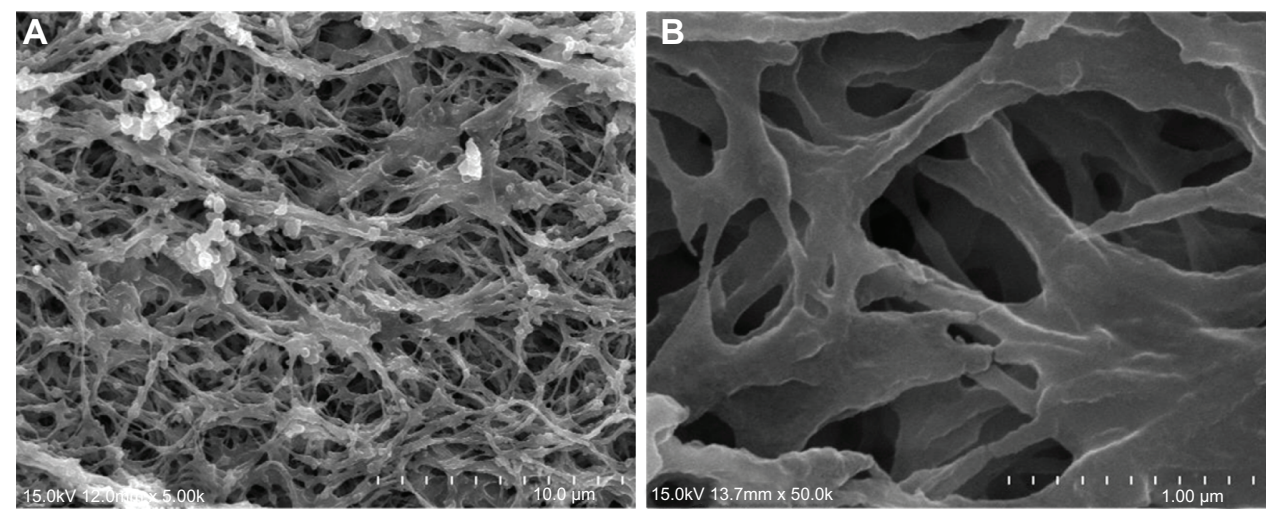

Figure 6 SEM images of an Fbg sheet reveal highly porous micro- and nanostructured networks ( $A$ and $B$ shown at different magnifications). Abbreviations: Fbg, fibrinogen; SEM, scanning electron microscope. 
regeneration. ${ }^{6}$ Recently, Lei et al developed a novel Fbnbased hydrogel to deliver concentrated and nonaggregated nonviral genes, demonstrated by in vivo study. ${ }^{62}$ The hybrid hydrogel, made with Pluronic F127-Fbg, showed superior physical properties for in vitro cell culture. Moreover, the hybrid hydrogel retained Fbg biocompatibility with added mechanical strength, and at the same time, Pluronic F127 did not lose its unique self-assembly properties. ${ }^{63}$ Fbg- and Fbn-based hydrogels have remarkable merit over other types of natural polymer hydrogels (gelatin and collagen) in that they can be made available autologously, thus avoiding viral infection transmission and the potential risks of foreign body reaction. ${ }^{61}$ Fbn hydrogels seeded with smooth muscle cells, ${ }^{64}$ skeletal muscle cells, ${ }^{65}$ and chondrocyte cells ${ }^{66}$ have been used to produce engineered tissues with a high degree of mechanical strength.

\section{Fbg and Fbn tubes as vascular graft}

Our laboratory constructed small-diameter Fbg grafts as biodegradable and biocompatible scaffolds for use in microvascular tissue engineering, using a tubular gelsolvent extraction method. The tube showed a rough outer surface and smooth inner surface. The measured inner and outer diameters of the Fbg microtube were approximately
750-850 $\mu \mathrm{m}$ and 950-1050 $\mu \mathrm{m}$, respectively (Figure 7) (data unpublished).

\section{Fbg/Fbn-synthetic polymer composites as micro/nano scaffolds}

Synthetic polymers ${ }^{67}$ and copolymers ${ }^{68}$ have been frequently used in the field of tissue engineering, as they have ability to precisely control the mechanical strength of the matrices, but often, these polymers provide inadequate cell regulation for specific cellular events. Fbg and Fbn have been widely mixed/ blended with other natural/synthetic polymers to fabricate different composite biomaterials for vascular regeneration, bone regeneration, chronic wound healing, osteogenesis, and reepithelialization. ${ }^{69-71}$ In addition, biocomposite materials acquire adequate mechanical strength, enhanced cell adhesion, proliferation, and ECM production as well as the potential regulation of other cellular process activities for specific cellular events.

PEG-Fbg composites furnish attachment motifs for smooth muscle and endothelial cells adhesion; these cells have demonstrated their capability to pass through scaffolds to carry out their respective functions. ${ }^{60}$ The PLGA microspheres immobilized with Fbg matrix have shown enhanced chondrocyte proliferation and ECM
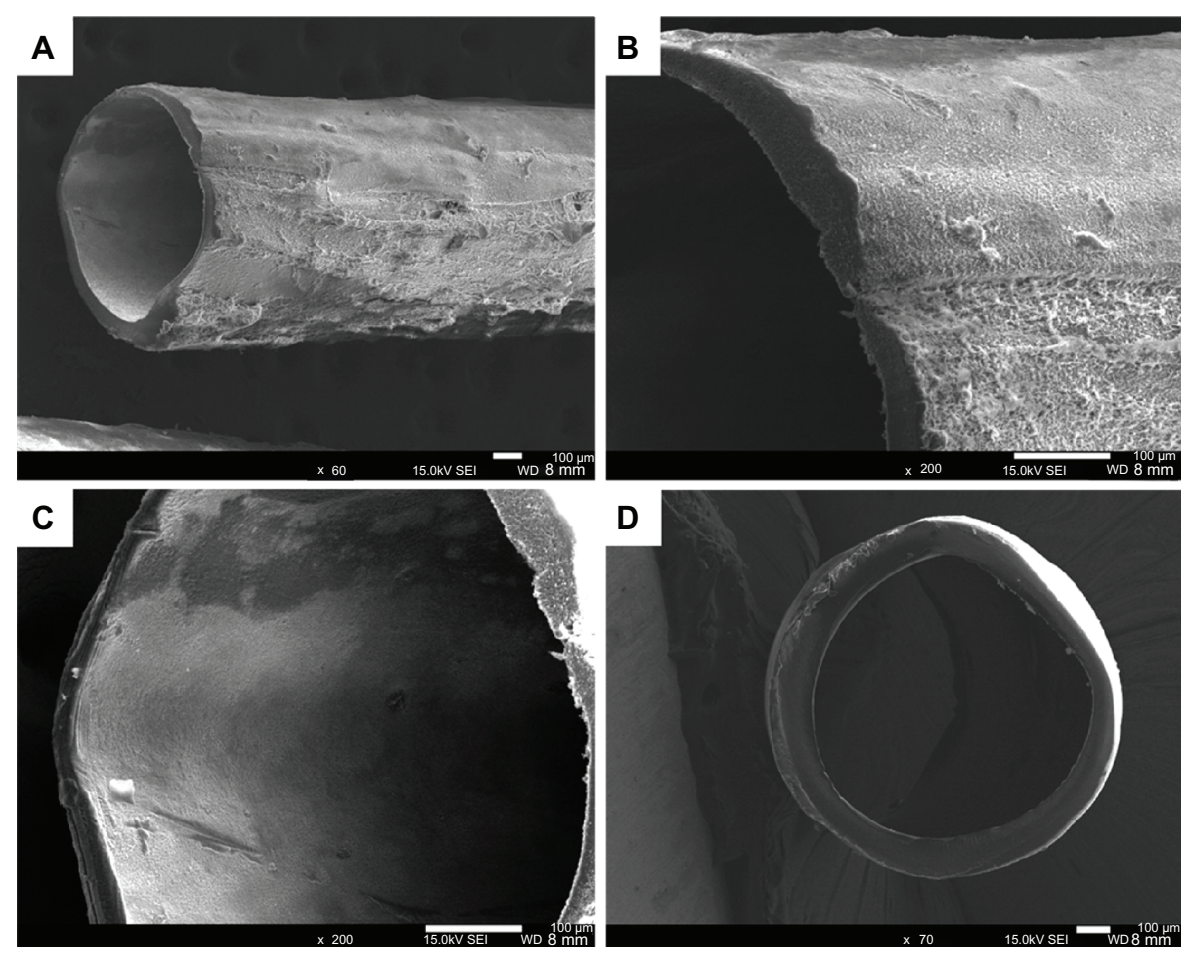

Figure 7 SEM images of a Fbg microtube. (A) The outer morphology of the tube shows the rough surfaces; (B) Magnified image of microtube shown in (A); (C) The tube's inner surface was revealed to be much smoother than the outer surface; (D) The cross-sectional SEM image reveals the round shape, with approximately uniform wall thickness. (data unpublished).

Abbreviations: Fbg, fibrinogen; SEM, scanning electron microscope. 
production.${ }^{61}$ PEGylated albumin combined with PEGylated Fbg hydrogel was shown to reveal comprehensive drug release and degradation properties. ${ }^{72}$ Macro/microporous biphasic calcium phosphate granules combined with Fbn glue were shown to provide a moldable and selfhardening biocomposite, which has been used in types of orthopedic and maxillofacial applications, due to their osteoconductive properties. ${ }^{73}$ Fbn-PLGA composites were shown to encourage early chondrogenesis in rabbit articular cartilage, and this indicates that Fbn-PLGA might act as a possible cell delivery vehicle to promote articular cartilage development. ${ }^{58}$ Frisman et al reported a method for fabricating nanostructured biocompatible and biosynthetic polymeric hydrogel by cross-linking PEG and Fbg. The constructed 3-D hydrogel provided enhanced cellular behavior and superior mechanical strength. ${ }^{74}$ Polycaprolactone valves coated with Fbn demonstrated proper opening and closing dynamics in cardiac tissue engineering, with good biocompatibility, ${ }^{75}$ and in a further study, Fbn-polyurethane microporous hydrogel cultured with osteogenic cells exhibited promising results in articular tissue development in vivo. ${ }^{76}$

The delivery of genetic material and DNA by polymerbased hydrogels would add to the applications in the field of gene therapy and cancer therapy. ${ }^{77}$ However, the delivery of
DNA through a synthetic cationic polymer ("polyplexes") hydrogel has not previously succeeded because of high aggregation and inactivation of the cationic polymer inside the hydrogel matrix. ${ }^{78}$ But, the same polymer hydrogel when functionalized with Fbg, could be effectively used to deliver concentrated DNA without aggregation. ${ }^{62}$ Osathanon et al reported a novel method of constructing a calcium phosphate-Fbn hydroxyapatite-based composite scaffold, which revealed a tightly interconnected network and a more porous structure, and the biodegradable composite supported primary osteoblast-like cell adhesion, proliferation, and differentiation in bone tissue engineering, in vitro and in vivo. ${ }^{79} \mathrm{Fbg}$ and $\mathrm{Fbn}$ also have been combined with different types of synthetic polymers, such as polydioxanone, ${ }^{48}$ poly( $($-caprolactone $),{ }^{80}$ etc. Other composite materials that have been used in similar applications are listed in Table 2.

\section{Fbg/Fbn-natural polymer composites as micro/nano scaffolds}

These combination natural polymer matrix-based cell delivery systems have become a promising approach in the development of many current cell therapies, as such systems exhibit synergistic effects on cellular interaction, promoting integration into host tissue, as well as offering variable material

Table 2 Delivery systems for different biomolecules and cell types using Fbg/Fbn composites, and their tissue engineering applications

\begin{tabular}{|c|c|c|c|c|}
\hline $\begin{array}{l}\text { Micro/nano scaffolds/ } \\
\text { composites }\end{array}$ & $\begin{array}{l}\text { Types of growth } \\
\text { factor/cell delivery }\end{array}$ & $\begin{array}{l}\text { Targeted } \\
\text { tissue }\end{array}$ & Respective function & Ref \\
\hline Fbn-calcium phosphate & rhBMP-2 & Bone & $\begin{array}{l}\text { The highly interconnected porous composite promoted } \\
\text { bone formation in mouse calvarial defect model }\end{array}$ & 79 \\
\hline Fbg-polydioxanone & $\begin{array}{l}\text { Bladder smooth } \\
\text { muscle cells }\end{array}$ & Urologic tissue & Promoted cellular ingrowth and in situ urologic tissue regeneration & 48 \\
\hline Alginate-Fbn-hyaluronan & TGF- $\beta$ I & Cartilage & $\begin{array}{l}\text { Promoted chondrogenic differentiation of MSCs and sulfated } \\
\text { glycosaminoglycans synthesis, inducing cartilage tissue formation }\end{array}$ & 93 \\
\hline Silk-Fbn-hyaluronic acid & Human chondrocytes & Spinal disc & $\begin{array}{l}\text { Provided both mechanical strength and biochemical support for } \\
\text { nucleus pulposus cartilage formation }\end{array}$ & 91 \\
\hline Fbn-poly( $\varepsilon$-caprolactone) & $\begin{array}{l}\text { Human umbilical vein } \\
\text { endothelial cells }\end{array}$ & $\begin{array}{l}\text { Cardiovascular } \\
\text { tissue }\end{array}$ & $\begin{array}{l}\text { The composite scaffold provided integrated physicochemical character } \\
\text { with biomimetic property for cardiovascular tissue regeneration }\end{array}$ & 80 \\
\hline Fbn-poly(L-lactide) & Auricular chondrocyte & Cartilage & $\begin{array}{l}\text { The porous scaffolds furnished significantly higher level of rabbit } \\
\text { auricular chondrocyte viability, with better mechanical strength } \\
\text { and cytocompatability for cartilage tissue engineering }\end{array}$ & 61 \\
\hline PEtU-PDMS/fibrin & VEGF and bFGF & Blood vessels & $\begin{array}{l}\text { The composite stimulated new blood vessels formation in ischemic } \\
\text { tissues in general and in particular, in ischemic cardiac tissues }\end{array}$ & 94 \\
\hline Collagen-hyaluronan-Fbn & Chondrocytes & Cartilage & $\begin{array}{l}\text { The implanted scaffold enhanced cartilage regeneration } \\
\text { of osteochondral defects by the supporting of the hyaline } \\
\text { cartilage formation }\end{array}$ & 95 \\
\hline Fbg-alginate & Chondrocytes & Cartilage & $\begin{array}{l}\text { Human articular chondrocytes mixed with Fbn-alginate composite } \\
\text { promoted sufficient chondrocyte proliferation and differentiation } \\
\text { in the formation of specific cartilage matrix }\end{array}$ & 92 \\
\hline Fbn-collagen-Fbn & $\begin{array}{l}\text { Fibroblast, keratinocyte } \\
\text { and epidermal }\end{array}$ & Skin & $\begin{array}{l}\text { The constructed composite scaffolds containing fibroblasts, } \\
\text { keratinocytes, and epidermal cells promoted rapid skin regeneration }\end{array}$ & 86 \\
\hline
\end{tabular}

Abbreviations: bFGF, basic fibroblast growth factor; Fbg, fibrinogen; Fbn, fibrin; MSCs, mesenchymal stem cells; PEtU-PDMS, poly(ether)urethane-polydimethylsiloxane; rhBMP, recombinant human bone morphogenetic protein; TGF, transforming growth factor; VEGF, vascular endothelial growth factor. 
properties with good degradation kinetics ${ }^{81}$ In this section, we discuss $\mathrm{Fbg} / \mathrm{Fbn}$-natural polymer composites and their application in tissue regeneration therapies. In one study, Fbn-gelatin composite film was shown to exhibit a high equilibrium content of water, which could effectively improve the efficacy and properties of the matrix when applied as a wound dressing. ${ }^{82}$ In other studies, a physiologically coated Fbn-chitosan gelatin composite film was shown to provide a fibrous and porous structure with a high water absorption capacity, which could improve the encapsulation efficacy of hydrophilic protein and peptides. ${ }^{83}$ Hepatic cell-seeded Fbggelatin matrix stabilized by thrombin exhibited a very high compressive strength. The study also suggested that Fbn could be a favorable biological component for cell assembly/delivery compared with other natural protein-based scaffolds. ${ }^{84}$ Fbgand thrombin-coated collagen patches were used as a topical hemostatic agent and were applied for rapid hemostasis and wound closure after procedures such as liver, thoracic, neuro-, kidney, spleen, plastic, and minimally invasive surgery, in vivo ${ }^{85}$. By combining collagen, chitosan, and Fbn, Han et al prepared novel asymmetric porous scaffolds. ${ }^{86}$ In other studies, Lorusso et al reported that Fbg/thrombin-coated collagen patches were effectively used for the control of severe intraoperative pulmonary hemorrhage and air leakage after correction of a ruptured thoracic aortic aneurysm. ${ }^{87}$ Recently, a Fbn-chitosan composite loaded with human fibroblasts showed good cells spreading effect and ECM interaction..$^{88}$ Both Fbnand collagen-based vascular grafts could be used as substitutes for bypass grafts or as models for vascular studies. ${ }^{89}$ Very recently, Zhou et al successfully demonstrated the controlled delivery of recombinant human epidermal growth factor (rhEGF) using a Fbn-chitosan composite - the composite achieved a high protein loading efficacy due to the presence of chitosan and a lower initial burst release due to the Fbn. ${ }^{90} \mathrm{Fbg}$ and Fbn have also been blended or coated with different natural polymers, such as poly(L-lactide) ${ }^{61}$ silk fibroin,${ }^{91}$ alginate, ${ }^{92}$ etc. Other such composites are listed in Table 2.

\section{Cross-linking of Fbg and Fbn micro/ nanoscaffolds}

In tissue engineering and regenerative medicine, shape stability is a significant factor for specific medical applications, such as those relating to bone, blood vessel, and nerve regeneration. ${ }^{11,96}$ Fbg micro/nanoscaffolds can lose their structure within a few days through degradation by various protease enzymes, such as plasmin and trypsin, in vitro and in vivo. ${ }^{97,98}$ For complete regeneration of various body tissues, including cartilage and bone, scaffolds should maintain their size and shape in the long term in order to deliver comprehensive mechanical strength. In order to achieve such strength, Fbg and Fbn scaffolds have been cross-linked with different chemical and biological agents.

In 1963, Mihalyi was the first to describe a crosslinking procedure for bovine Fbg, using formaldehyde. ${ }^{99}$ A few years later, in 1975, human Fbg cross-linking was introduced by Furlan and Beck, using glutaraldehyde and tetranitromethane. They further confirmed the participation of different chains $(\alpha, \beta$, and $\gamma)$ in intermolecular cross-linking, by performing sodium dodecyl sulfate-polyacrylamide gel electrophoresis (SDS-PAGE), the results of which evidenced that enhanced intermolecular cross-linking occurred when high concentrations of glutaraldehyde were used. ${ }^{100} \mathrm{Fbn}$ clots are naturally cross-linked through the inclusion of activated transglutaminase (factor XIII), which forms covalent crosslinking between glutamyl and lysyl residues of adjacent Fbn molecules ${ }^{45}$ but factor XIII is comparatively expensive. On the other hand, glutaraldehyde is commonly used as a cross-linking agent for natural proteins and is currently used to hasten tissue regeneration by fixing collagenous tissue. ${ }^{101,102}$ Glutaraldehyde is also reasonably inexpensive and has the ability to be cross-linked rapidly over large distances, with a broad range of amino groups. ${ }^{103}$ However, aldehydes are non-zero-length cross-linkers that can induce poly- or bifunctional cross-links into the protein structure during cross-linking. Moreover, aldehydes could leach toxic substance after carrier degradation, thereby presenting an increased risk of cytotoxicity and material calcification. ${ }^{101,102}$ To compare cellular toxicity and other physical properties, Sell et al cross-linked bovine Fbg scaffolds using two different cross-linkers, namely glutaraldehyde vapor and 1-ethyl-3-(3-dimethylaminopropyl) carbodiimide hydrochloride) (EDC). ${ }^{45}$ The EDC cross-linked scaffolds showed considerably increased peak stress modulus values and less toxicity with significant sustained degradation, when compared with glutaraldehyde cross-linked scaffolds, in vitro. Dare et al cross-linked Fbn hydrogels incorporated with human articular chondrocytes using naturally-occurring genipin, and the result demonstrated a superior mechanical strength, with excellent gene expression, ECM production, and a slower rate of degradation. Moreover, genipin crosslinked-Fbn hydrogel did not noticeably affect cell viability and importantly, increased the shear moduli and dynamic compression of the hydrogel. ${ }^{104}$ Recently, Fbg nanoparticles were cross-linked with calcium chloride and were shown to have potential as a promising therapeutic carrier for sustained anticancer drug release in vitro. ${ }^{12}$ 
EDC is a water soluble and zero-length cross-linker. Most of all, EDC cannot be incorporated into protein molecules, as it can be simply washed away as a water soluble urea derivative, thereby decreasing the potential for cytotoxic effects. ${ }^{101,102}$ Fbg microspheres that were crosslinked with various concentrations of EDC (1, 3, 5 and $10 \mathrm{mM}$ ) revealed a slower rate of degradation with increasing EDC concentrations. ${ }^{9}$ Compared with this, nanostructure aligned and highly porous Fbg microfibers that were crosslinked with EDC showed slower fibrinolytic degradation. Thus, increased Fbg cross-linking is not only based on the concentration of cross-linkers, but also depends on scaffold structural characteristics. For example, Fbg scaffolds made with nanostructures attained higher cross-linking compared with microstructures because of their higher exposure of Arginine and Lysine residues, which are abundantly present on the Fbg surface. To minimize or reduce the proteolytic degradation of Fbn, researchers have commonly used Fbn degradation inhibitors and their stabilizers, such as factor XIII, aprotinin, and e-amino-n-caproic acids, ${ }^{59,65,93,105}$ along with sufficient amounts of thrombin and calcium, which all prevent excessive degradation of Fbn. ${ }^{106}$

Tissue plasminogen activator can activate plasminogen to active plasmin (serine protease), which in turn, degrades Fbg and Fbn by cleaving the carboxyl terminal peptide bond of the Arginine or Lysine residues; therefore, for long-term degradation there needs to be an increase in the number of peptide bonds with suitable cross-linking agents. ${ }^{99,101,102}$ Various studies have disclosed the potential of Fbg and Fbn scaffolds for cell viability, gene expression, and ECM production. However, to obtain better tissue engineering results, scaffolds should maintain their size and shape for prolonged periods, and to achieve that, it is necessary that they be stabilized with an appropriate cross-linking agent. Furthermore, the rate of degradation can be controlled by either increasing the concentration of cross-linking agents or by producing a nanostructured scaffold.

\section{Cancer therapy}

Cancer remains an incurable disease, and there are more than 10 million new patients identified every year. On the other hand, due to the development of new technology and surgical intervention (radiation and chemotherapy), the death rate related to cancer has been declining for the past few years. However, chemotherapeutics kill normal cells and cause a variety of toxicities to patients. To minimize this, many research groups have focused their research towards biodegradable polymer carrier (micro/nano) drug delivery systems, and many have attained satisfactory results. ${ }^{107}$ Among the biodegradable polymer carriers, Fbg-based micro/nano carriers are widely used in cancer treatment. Fbg and Fbn can inhibit the progression of cancer cell growth by countering excessive coagulation in and around tumor tissues. ${ }^{108}$ Because of this, Fbg-based micro- or nanocarriers are widely used in cancer treatment.

The anticancer drug-loaded Fbg micro/nano carriers have shown promising effects on various cancer cells. In one study, water soluble, 5-fluorouracil-loaded Fbg microspheres were effectively used as a novel injectable drug delivery system for anticancer treatment and expressed sustained release for more than 5 days, as demonstrated by in vitro experiment. ${ }^{39}$ The same research group demonstrated doxorubicin release in mice, and positive results were observed on the basis of animal survival data. The doxorubicin solution-injected mice showed decreased lifespan, with $50 \%$ dead at 10 days and no survivors after 28 days, whereas doxorubicin-loaded-Fbg-microsphereinjected mice showed significantly increased lifespan, and $50 \%$ mortality occurred after 60 days. ${ }^{36}$ Similarly, micronized droplets of olive oil containing docetaxel coated with Fbg markedly improved the therapeutic efficacy of docetaxel for the treatment of mammary tumor growth. ${ }^{109}$ Recently, Fbg nanoparticles were effectively used as a carrier for 5-fluorouracil ${ }^{42}$ and in curcumin delivery. ${ }^{110}$

\section{Fbg and Fbn micro/nano scaffolds integrated with biomolecules and cells for tissue engineering applications}

An engineered scaffold should be biocompatible, provide sufficient mechanical strength for the specific application, and give the necessary functional support for cell growth and survival. In 3-D matrices, cell growth would be different from that on a 2-D/flat scaffold surface. When cells are growing in a 3-D scaffold, the third dimension provides another direction for cell-cell interactions, cell migration, and cell morphogenesis, all of which are essential in regulating cell cycles and tissue functions. For enhanced tissue regeneration the scaffold also needs to be grafted/immobilized with growth factors, other biomolecules, or different cells that can accelerate tissue regeneration and improve the function of the regenerated tissue through either direct release of biomolecules or via the secretion of proteins from immobilized cells. Growth factors are tissue-promoting agents that show therapeutic potential for various types of tissues regeneration (skin, nerve, vascular, dental, cartilage, bone, oral, and craniofacial) as well as for 
"therapeutic regeneration" processes. ${ }^{111-113}$ For example, in the treatment of chronic wounds, FGF and VEGF were successfully used in a bioartificial dermal substitute to improve angiogenesis through soft-tissue formation and collagen synthesis, in preclinical trials. ${ }^{14,115}$ Similarly, VEGF has been used in the treatment of new blood vessel formation and cardiac ischemia, in different clinical trials and animal models. ${ }^{112,116,117}$ Furthermore, local administration of FGF-basic can stimulate wound healing, as has been detailed by clinical trials. ${ }^{118,119}$ However, the direct administration of growth factors have drawbacks, such as rapid clearance from the injected or implanted area (due to the administration of a more soluble form), faster rates of degradation, and short half-lives (usually less than 1 hour). ${ }^{120}$ To overcome this problem, the natural polymer-based delivery system has emerged, as biopolymers can stabilize growth factors, allowing for their release in a controlled manner. ${ }^{121}$ The following section describes growth factor- and cell-loaded Fbg and Fbn scaffolds which have been used in a diverse range of tissue regeneration applications. The schematic diagram in Figure 8 illustrates the general representation of growth factors and cell delivery from designed scaffolds, for a number of tissue engineering applications.

\section{Nerve tissue regeneration}

Peripheral nerve damage/injury often requires neural reconstruction, and the ability of the spinal cord to regenerate after injury is limited. From a clinical viewpoint, a number of scientific articles suggested that tissue engineering is a favorable option to facilitate the process of nerve repair/regeneration. ${ }^{7,24,121,122}$ The neurotrophins are a family of growth factors that maintain neuron survival and axonal elongation, ${ }^{123}$ and include NGF, neurotrophin-4/5, neurotrophin-3 (NT-3), and brain-derived neurotrophic factor (BDNF). ${ }^{124}$ NGF can be used to treat various neurodegenerative disorders, such as Alzheimer's disease, Huntington's disease, and peripheral nerve injuries; NGF also plays an essential role in sensory and sympathetic neuron endurance and preservation. ${ }^{125}$ NGF has been explored as a significant drug for the treatment of spinal cord injury, to stimulate neural sensory fiber growth around chronic wounds. ${ }^{126}$ NT-3 fulfills a central role in neurogenesis (by stimulating the differentiation of new neurons) and promotes corticospinal axonal growth. ${ }^{127}$ NT-3 has been used as a potential therapeutic agent for spinal cord injury because it encourages neural cell growth and survival in the development of the corticospinal tract. ${ }^{123}$

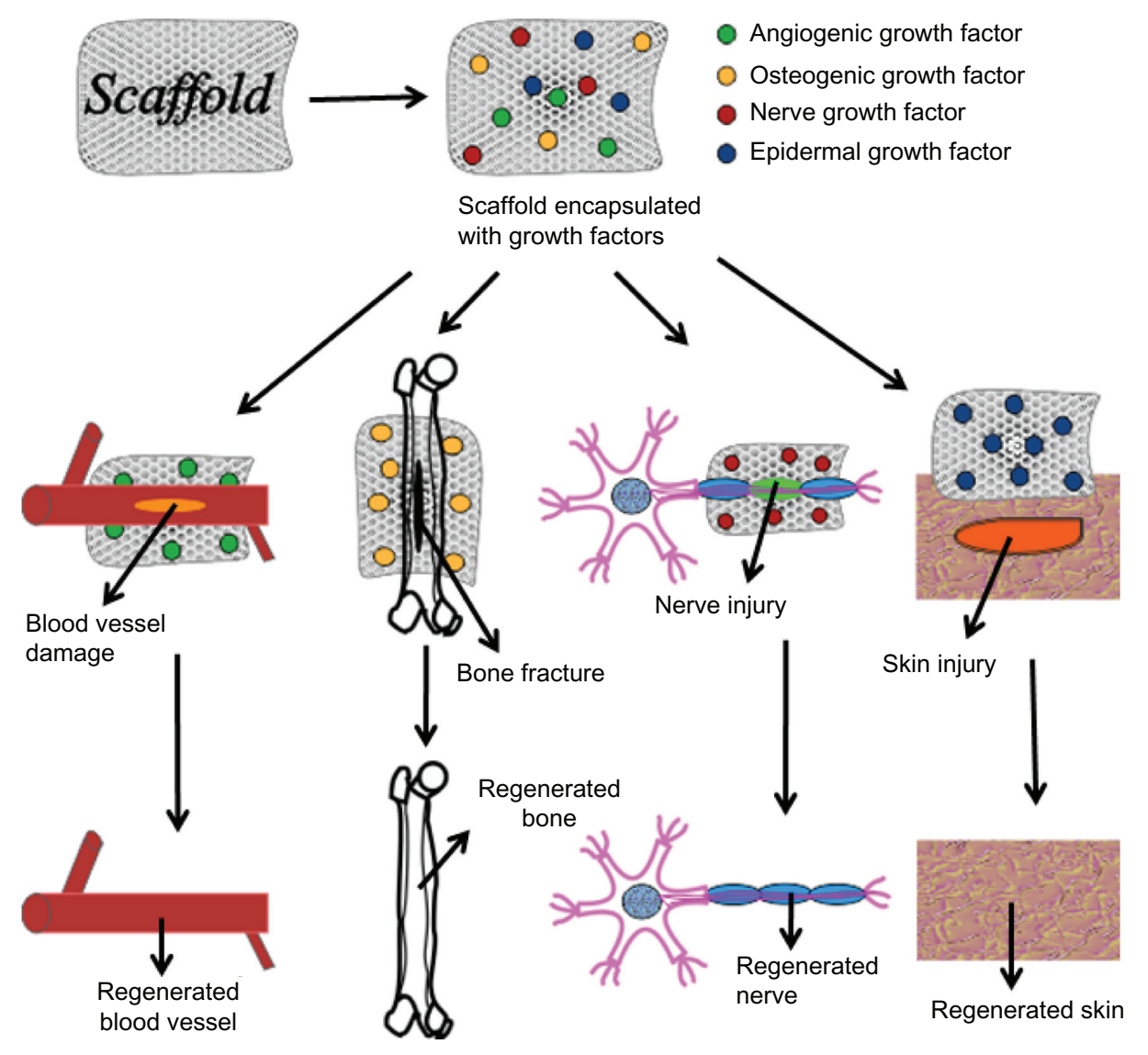

Figure 8 Specific growth factor-loaded scaffolds used for regeneration of various tissues. 
The direct injection of neurotrophins at the site of spinal cord injury has been shown to promote neuronal growth; however, the regenerative efficacy was reduced by various factors, such as loss of neurotrophins into the cerebrospinal fluid, aggregation, and proteolysis, and so this may not be applicable for continuous functional restoration and neuron regeneration. ${ }^{122,128}$ To achieve long-term protein release as well as neuronal fiber sprouting, a suitable polymer scaffold will release NGF at the specific site and at a specific rate for a specific duration. ${ }^{121,129,130}$ The specific cell- and proteinbinding characteristics of Fbg and Fbn scaffolds could be suitable for application to nerve conduit, providing an optimal microenvironment as well as molecular and electrical cues for efficient neural cell regeneration., ${ }^{7,131}$

NT-3-loaded Fbn scaffolds initiate regenerative responses and promote axonal growth by increasing neuronal fiber sprouting and cell migration into the injury site; moreover, the scaffold can dramatically reduce glial scar formation at the white matter border of the lesion, as demonstrated in one in vivo animal experiment. ${ }^{122}$ In another study, a heparinfunctionalized Fbn scaffold immobilized with NT-3, via noncovalent interactions, delivered protein in a controlled fashion to an injured spinal cord, as studied in an adult rat model. Furthermore, the heparin-Fbn-affinity-based system released the drug through cell-mediated processes and restricted drug loss by diffusion. Therefore, the controlled delivery of NT-3 from Fbn scaffolds indicated improved neuronal fiber development/growth. ${ }^{132}$ The $\beta$-NGF-incorporated Fbn matrix provided enhanced nerve regeneration by effectively releasing NGF via the proteolytic activity of plasmin, and this kind of delivery system represents an improvement in nerve regeneration. ${ }^{133}$ Further, it was shown that Fbn glue soaked with NT-3 expressed better dorsal root regeneration in the spinal cord and offered a strategy for injured spinal reflex arc stimulation. This study also suggested that Fbn glue is an effective exogenous vehicle for the intraspinal delivery of neurotrophic growth factors. ${ }^{134}$ Fbn implantation with NT-3 induced neuronal fiber formation in rat spinal cord lesions. ${ }^{124}$

In artificial nerve regeneration, other than nerve stimulating factors, stem cells, such as Schwann cells (SCs) and MSCs, also could enhance nerve growth by, themselves, secreting nerve stimulating factors. ${ }^{135}$ MSCs can be induced to differentiate into $\mathrm{SCs}$ and to promote the regeneration of injured sciatic nerves. ${ }^{136} \mathrm{SCs}$ have a prominent specific role in nerve tissue regeneration because they can secrete NGF and other nerve regenerating proteins, which can enhance the survival of cholinergic neurons. ${ }^{137}$ Because of their protein secretion advantage, these cells have a potential use in the treatment of various neurodegenerative disorders, such as Alzheimer's and Huntington's disease. ${ }^{126}$ Both MSC- and SC-seeded polyhydroxybutyrate-fibrin (PBH-Fbn) nerve conduits have demonstrated enhanced continuous proliferation and differentiation throughout the conduit over conduits fabricated using only $\mathrm{PBH}$, in vivo. ${ }^{7}$ Fbn scaffolds cultured with embryonic stem cells stimulate neurons and oligodendrocytes and have been used as a platform for neural tissue engineering. ${ }^{125}$ It has been suggested that both Fbg and Fbn can be an excellent scaffold for nerve regeneration, and in particular, Fbn gel has been demonstrated to encourage axonal regeneration and cell migration in short-gap nerve injury. ${ }^{138}$

\section{Bone and cartilage tissue regeneration}

The poor healing potential of cartilage and bone has been a well-known concern in orthopedic surgery. ${ }^{139}$ On the other hand, studies of bone tissue engineering have looked at regeneration of osteoblasts to accelerate fracture healing, correction of major defects in bones that cannot usually be rebuilt, spinal cord strengthening, and bone mineral density loss by aging. ${ }^{6,25,79,140}$ The treatment of bone loss has been conventionally managed using direct bolus injection of cells, open implantation of bone-forming cells, and scaffold-based drug delivery systems. ${ }^{141}$ The skeletal system holds numerous growth factors, including TGF- $\beta$, FGF, VEGF, insulin-like growth factors (IGF-I and IGF-II), platelet-derived growth factor (PDGF) and BMPs, that contribute to cartilage and bone repairs. ${ }^{141}$ Among these peptide growth factors, BMPs play a significant role in mediating the growth, remodeling, and regeneration of the skeleton system, due to their better osteoinductive properties, ${ }^{142}$ and also in stimulating osteoblast proliferation and skeletal muscle component synthesis (collagen). ${ }^{143}$ bFGF has mitogenic and angiogenic properties for cartilage regeneration that have been consistently confirmed. ${ }^{144}$ TGF can increase bone thickness, ${ }^{145}$ and the anti-inflammatory properties of TGF- $\beta 1$ have been shown to stimulate cartilage regeneration via chondrocyte differentiation. ${ }^{146}$ The IGFs are also viewed as one of the most significant groups of skeletal growth factors, due to their important actions on bone and cartilage cell function, repair, and regeneration. ${ }^{147}$

Since 1980, Fbn has been extensively used for bone repair/regeneration; its various characteristics, including slow drug release and enhanced cellular growth, have made it a suitable carrier for different orthopedic surgery applications. ${ }^{148}$ Fbn provides a natural environment for boneforming cells, ${ }^{149}$ and Fbn glue was effectively used because 
of its chemotactic, hemostatic, and mitogenic properties. ${ }^{148}$ Recently, in bone tissue engineering, Fbn scaffolds loaded with different osteogenic growth factors and bone forming cells have been found to promote cartilage structure and viability. ${ }^{68}$ In one study, BMP-2-immobilized Fbn gel, via cell-activated plasmin, resulted in a significant improvement in bone-defect healing. ${ }^{150}$ Elsewhere, a heparin-incorporated Fbn-FN matrix model was reported to provide an optimal delivery system for BMPs, where the Fbn matrix acted as the platform to accommodate the infiltrating tissue, while FN established a connection between Fbn and heparin and also provided an adhesion site for tissue-repair cells. ${ }^{151}$ Kang et al reported that Fbn scaffold itself has good bone cell inductive properties, and when it's loaded with peptide growth factors, such as with BMP-2 shows enhanced bone regeneration. ${ }^{152}$

Recently, bone marrow cells and MSCs were incorporated into Fbn scaffolds to encourage meniscal healing in an animal model. ${ }^{153-156}$ MSCs are multipotent and are capable of producing mesenchymal tissues like bone, cartilage, and tendon. ${ }^{50}$ The MSC-loaded Fbn matrix was used as an autogenous bone graft because MSCs can easily undergo many cycles of cell division without losing their osteogenic capacity/properties, a feature that holds strong implications for orthopedic surgery and oral and maxillofacial reconstructions. ${ }^{157}$ MSCs-Fbn microbeads secrete mineralized ECM around the implantation area, and bone formation is promoted by secretion of osteogenesis (ascorbic acid, $\beta$-glycerophosphate, and dexamethasone) and osteoblast growth factors. ${ }^{158}$ Isogai et al reported that periosteal cell-cultured Fbn glue stimulated new bone formation at heterotopic sites, in an in vivo animal study. ${ }^{159}$ In another study, Fbn hydrogel mixed with freshly isolated bovine chondrocytes showed coherent cartilaginous ECM production and distribution. ${ }^{106}$ Currently, studies concerned with the fabrication of Fbn-based scaffolds for bone and cartilage regeneration have observed the advantages of this material when used to deliver multiple osteogenic growth factors and cells. ${ }^{6,92,104}$ These advantages include the stimulation of osteoblasts, osteocytes, and osteoid cell proliferation, extending the application of such procedures beyond the treatment of isolated defects and fractures. However, effective bone and cartilage regeneration depend on the associated drug/cell delivery systems, the duration of biological cues release, and biochemical interactions between cells and the polymer carrier.

In bone tissue engineering and orthopedic surgery, Fbn composites have been widely used because of their good adhesive properties and their reduction of blood loss intra- and postoperatively as well as for their ease of manipulation. ${ }^{160,161}$ Fbn-coated calcium phosphate granules implanted in male Swiss albino mice depicted new bone formation and good healing responses at the extraskeletal site. Furthermore, bone formation was found to be conspicuous on Fbn-coated granules, whereas the uncoated granules did not show any de nova bone formation. ${ }^{162}$ The Fbn-based biocomposite scaffolds seemed to stimulate mineralization on the Fbn network that was present within the ceramic grains; moreover, it was suggested Fbn glue could stabilize the granules at the implantation site, to mold the bone defects without an empty space and also provide favorable microenvironmental conditions for the osteogenic cells, leading to rapid bone healing effects. ${ }^{73} \mathrm{Fbn}$, calcium phosphate, and hydroxyapatite-based composites could effectively induce bone repair. However, for better bone tissue regeneration, scaffolds should have well-controlled micro/ nanopore interconnected networks, so that they can provide ease of cell attachment and proliferation. ${ }^{73}$ In one study, the porous scaffold developed by a Fbn-calcium phosphate composite showed tightly interconnected networks and porous structure. The biodegradable composite supported primary osteoblast-like cell adhesion, proliferation, and differentiation in bone tissue engineering, in vitro and in vivo experiments. ${ }^{79}$ In another study, the combination of Fbn sealant and ceramic depicted a synergic effect in bone and cartilage tissue engineering; also the bioceramics showed enhanced physical properties compared with ceramic alone. ${ }^{163}$

\section{Vascular tissue regeneration}

The selection of suitable biomaterials that are capable of inducing endothelialization and blood vessel formation is significant in therapeutic regeneration, especially for vascular tissue engineering. Angiogenesis is another eminent concern for vascular tissue engineering; angiogenesis is the process by which the preexisting vasculature gives form to new blood vessels. The stimulation of neovascularization is based on the various angiogenic factors, and each angiogenic factor would function respectively, to make perfect functional blood vessels. Several growth factors have been applied to therapeutic angiogenesis, including the angiopoietins, hepatocyte growth factor (HGF), FGF (acidic and basic), and VEGF. Among these stimulators, VEGF is one of the major groups of proteins involved in blood vessel formation, by directly stimulating endothelial cells migration and proliferation; the VEGFs include VEGF-A, -B, -C, -D, -E and -F. ${ }^{164}$ After VEGF, the FGFs are the most widely applied proteins for restoration of the blood supply in ischemic tissues, and these stimulate reendothelialization of wounded arteries, ${ }^{165-167}$ in particular, 
bFGF binds to endothelial cells and enhances their migration and proliferation for new blood vessel formation. ${ }^{168,169} \mathrm{HGF}$, neurotrophin, erythropoietin, and IGF are all also used for targeted vascular repair. ${ }^{68}$ In addition to other growth factors, such as PDGF, epherin B2, and angiopoietin 1, these help to stabilize the newly shaped blood vessels, by recruiting smooth muscle cells to the nascent endothelial capillary. ${ }^{170}$ Angiopoietins 1 and 2 function through the Tie2 receptor, which controls signal survival, migration of endothelial cells, regulation of blood vessel remodeling, and maintenance of vascular integrity. ${ }^{171}$ Generally, for new blood vessel formation around ischemic tissues or associated with implants, it is presumed that efficient neovascularization requires the sustained delivery of angiogenic proteins to settled tissue over a period of weeks. ${ }^{172,173}$

$\mathrm{Fbg} / \mathrm{Fbn}$ is a blood protein which has the ability to augment the biochemical and mechanical integrity of the scaffold for vascular regeneration. ${ }^{11}$ The enzymatic fragmentation of fibrin yields a variety of degradation products that are capable of inducing angiogenesis; in particular, Fbn fragment $\mathrm{E}$ is a potent angiogenic factor, which has been studied alongside chicken chorioallantoic membrane (CAM). ${ }^{70,164}$ In one study, the heparin-functionalized Fbn matrix immobilized with VEGF was shown to be highly effective in delivering the growth factor over a period of months. Moreover, the matrix maintained VEGF bioefficacy for long term better than the other polymeric systems. ${ }^{35}$ VEGF-grafted Fbn gel also showed enhanced therapeutic angiogenic outcomes, in a rabbit ischemic hind limb model. ${ }^{35}$ Elsewhere, covalently immobilized VEGF in a Fbn hydrogel revealed dosedependent protein release with excellent growth of endothelial cells, which further stimulated an angiogenic response in an ischemic region. ${ }^{174}$ The VEGF-modified Fbn gel was shown to induce new blood vessel formation in CAM. ${ }^{174}$ Similarly, bFGF-incorporated Fbn scaffolds have shown a comparatively slow release, for continuous angiogenesis. ${ }^{5}$ Fbn scaffolds derived from blood clots were used as a local injectable carrier for VEGF, as this approach prevents the initial burst-release issue and maintains a controlled release. ${ }^{175}$ Both VEGF- and bFGF-immobilized Fbn-based scaffold systems have shown increased neovascularization, with the establishment of more mature blood vessels compared with the delivery of single growth factor. ${ }^{176}$ Arkudas et al investigated whether VEGFand bFGF-immobilized Fbn gels significantly induce higher absolute blood vessels formation in an arteriovenous loop mode. ${ }^{177}$ Composite scaffolds made with poly(ether)urethanepolydimethylsiloxane/Fbn can also be effectively used as a sustained delivery system for angiogenetic growth factors. ${ }^{94}$
Both Fbg and Fbn contain binding sites for various angiogenic factors, including adipose-derived stem cells and bone marrow stem cells. ${ }^{178,179}$ Both Fbg and Fbn provide a high seeding efficacy with uniform cell distribution for certain stem cells, such as hematopoietic stem cells, endothelial progenitor cells, smooth muscle cells, and MSCs, which are potentially differentiated into vascular-promoting cells in vitro. ${ }^{180}$ Endothelial cell-seeded-Fbn-hydrogel-induced blood vessels were shown to achieve good mechanical strength, with significant production of collagen and elastin, and showed considerable vasoreactivity within 2 weeks when implanted into 12-week-old lambs. ${ }^{11}$ Similarly, a 3-D Fbn gel containing human aortic myofibroblast cells also resulted in good vascular development, with controlled degradation in vitro. ${ }^{65}$ Smooth muscle cells can easily bind with Fbn via integrin $\alpha_{\mathrm{v}} \beta_{3}$, evoking a number of biochemical responses, such as secretion of proteolytic enzyme and production of the extracellular matrices collagen and elastin, which lead to Fbn degradation and increased mechanical strength, respectively, aiding in the formation of blood vessels. ${ }^{181}$ Moreover, Fbnbased carriers immobilized with angioinductive cells and vascular-stimulating proteins can be effectively used in vascular repair and in the induction of angiogenesis. ${ }^{182}$

\section{Skin tissue regeneration}

Skin injury requires a coordinated communication of hemostatic and inflammatory systems, influenced by cytokines and other growth factors, which locally regulate cellular proliferation and skin restoration. ${ }^{183}$ A number of growth factors are involved in skin regeneration, such as EGF, FGF, keratinocyte growth factor (KGF), PDGF, and TGF- $\beta$, each of which has been studied for its promotion of wound healing. EGF is a powerful growth factor for epidermal cell growth and is widely used as a therapeutic agent for epidermal cell migration, proliferation, and for stimulation of skin reepithelialization. ${ }^{184}$ EGF can also promote the synthesis of collagen and other cell-adhesive materials through epidermal cell proliferation, leading to increased rates of wound healing. ${ }^{184,68}$ FGF has therapeutic potential for skin tissue regeneration; specifically, bFGF stimulates collagen synthesis, soft-tissue formation, and reepithelialization, as shown by in vivo study of animal models. ${ }^{118,185} \mathrm{FN}$ is another potent mitogen that plays a crucial role in wound healing; upon injury it is bound to Fbn and is deposited at the site of injury, coagulating blood and providing a provisional matrix for epidermal cell migration and differentiation. ${ }^{28} \mathrm{KGF}$ is also a member of the FGF family (FGF-7) and plays a significant role in epithelial 
development and the promotion of wound healing. ${ }^{186,187}$ The TGF- $\beta$ members includes three isoforms namely, TGF$\beta 1$, TGF- $\beta 2$, and TGF- $\beta 3$, which are involved in either scarfree healing or scaring repair.

$\mathrm{Fbg} / \mathrm{Fbn}$ is a natural wound healing matrix that provides 3-D cell-infiltration scaffolds and facilitates cell adhesion and migration within wound areas. ${ }^{18}$ During wound healing, Fbg could improve the verity of ECM proteins (hyaluronan and laminin) secretion which may additionally encourage the properties and function of engineered skin tissues. ${ }^{20}$ bFGF can be easily bound to Fbg and Fbn due to the specific interactions; the bFGF-grafted Fbg and Fbn play a role in fibroblast adhesion and spreading, as well as in proliferation, ECM synthesis, and reepithelialization. ${ }^{19}$ Fbn scaffold supplemented with TGF- $\beta 2$ was shown to improve the wound healing of cutaneous wounds compared with Fbn alone in an in vivo animal study. ${ }^{26}$ In another, recent study it was shown that PDGF-embedded Fbn gel enhanced wound healing in excisional wounds. ${ }^{188}$ Elsewhere, the application of an Fbn hydrogel cross-linked with KGF showed long-term, controlled release and accelerated healing, which are difficult to achieve through the normal healing process, in vitro and in vivo. ${ }^{189} \mathrm{Gwak}$ et al reported that the combined delivery of EGF and KGF accelerated rapid epidermal regeneration compared with therapy using either EGF or KGF alone. ${ }^{190}$ The combined therapy also resulted in significantly improved epidermal thickness compared with each separate therapy alone. EGFimmobilized Fbn scaffolds resulted in effective regeneration of keratinocytes. ${ }^{191}$ Zhou et al developed a novel Fbn-based delivery system for rhEGF delivery, which may have great potential in topical wound healing applications, such as burns, surface destructions, ulcer fissures, and blisters. ${ }^{90}$ Finally, Fbg matrix covalently cross-linked to FN with factor XIII was shown to stimulate macrophage, fibroblast, and endothelial cell migration at the site of tissue injury and is involved in full expression of macrophage immobilization. ${ }^{192-195}$

Fibroblast cells enrolled to the site of tissue injury are considered to be essential for successful skin regeneration. ${ }^{196}$ Human keratinocyte cells and melanocytes have also been evaluated for potential application in wound healing. ${ }^{197}$ Fibrocytes are believed to have diverse biochemical functions in wound healing processes and also are believed to induce angiogenesis in vitro and in vivo. ${ }^{198}$ Fibroblast-coated Fbn microbeads have been found to stimulate granulation in tissue formation, ${ }^{8}$ and keratinocytes suspended in Fbn matrix were successful in reconstituting full-thickness wounds, in both mouse and human. ${ }^{199}$ Keratinocyte cell-seeded Fbn gel secretes a major cytokine (TGF- $\alpha$ ) that promotes keratinocyte proliferation and initiates reepithelialization via the EGF-receptor/TGF- $\alpha$ pathway. ${ }^{200} \mathrm{~A}$ recent study revealed that transplantation of an autologous keratinocyte-suspended Fbn scaffold could be efficiently used in the treatment of chronic venous leg ulcers. ${ }^{29}$ Similarly, Fbn scaffolds incorporated with adenovirus encoding endothelial nitric oxide synthase (eNOS) were shown to enhance NO production at the site of diabetic wounds. ${ }^{201}$ The enhanced NO production stimulated angiogenesis, endothelial and epithelial cell proliferation, and cell migration. ${ }^{202}$

\section{Conclusion and future perspectives}

In the last three or four decades, a number of outstanding reviews and research articles have been printed on natural and synthetic polymers and their combination, which have significant relevance toward the development of drug delivery systems, cancer treatment, and tissue engineering applications. Specifically, protein-based polymer scaffolds containing micro/nanoporous structures have been the focus of this review, where Fbg- and Fbn-based micro/nanoscaffold systems with micro/nanoporous structures, exclusively used for tissue engineering applications, have been discussed. The advantages of these materials include their biocompatibility, biodegradability, and nonimmunogenicity, and together with their various cell-adhesive/binding properties have resulted in their widespread and successful application as a biomaterial. $\mathrm{Fbg} / \mathrm{Fbn}$-immobilized growth factors have been shown to be continuously released for several days in a controlled manner, resulting in a significant improvement in cartilage/bone, nerve, vascular, and skin regeneration/repair. The release of growth factors and other tissue-inductive proteins is only sufficient when there are enough cells at the site of injury to stimulate or respond to respective signals or regeneration. Once the severity of a wound is deep/thick, the local cell population may be inadequate to regenerate the wound, and so, extra cells must be introduced in order for complete repair to take place. This is one of the major indications for tissue engineering applications, and Fbg and Fbn scaffolds have proven to be useful candidates in vascular, cartilage, bone, skin and nerve regeneration. Various scaffold developments in our laboratory, such as Fbg microspheres, Fbg nanospheres, Fbg microfibers, highly porous Fbg sheets, and Fbg microtubes, could serve in further innovations in tissue engineering applications. The developed scaffolds showed good results in terms of biomolecule grafting, cell attachment, and cell proliferation in tissue engineering, and could play a significant role in artificial tissue constructs, especially in wound dressing preparation and in artificial vascular development. Fbg/Fbn scaffolds 
have some limitations, such as weak mechanical strength and quicker degradation rate; however, their mechanical strength can be improved through either mixing with other natural/synthetic polymers or incorporation of micro/ nanospheres and cells, while their quicker degradation can be controlled by various cross-linking methods. Next-generation scaffolds should be immobilized with growth factors, other biomolecules, and suitable cell lines so as to accelerate, augment, and support cell proliferation and differentiation, enhancing the regeneration of fully functional tissue. In conclusion, Fbg and Fbn as drug delivery carriers and tissue engineering scaffolds can be used to deliver the drug and growth factors in a controlled manner, and also can be used to deliver the variety of cells by local injection, which may accelerate tissue regeneration. However, the overall processes of wound healing and vascular repair are complex processes, and there are a plethora of factors that may be considered in the continuous advancement of tissue engineering.

\section{Acknowledgments}

This work was supported by a National Research Foundation of Korea (NRF) grant funded by the Korean government (MEST) (2012R1A2A2A03046819: Development of biodegradable and biocompatible nano-patterned microfibers and microtubes for skin and vascular tissue engineering) and the GRRC program of Gyeonggi province [GRRCKyungwon 2013-A01, Development of Microfluidic Chip for diagnosis of disease].

\section{Disclosure}

The authors report no conflicts of interest in this work.

\section{References}

1. Blombäck B, Hessel B, Hogg D, Therkildsen L. A two-step fibrinogen-fibrin transition in blood coagulation. Nature. 1978;275(5680): 501-505.

2. Bensaid W, Triffitt JT, Blanchat C, Oudina K, Sedel L, Petite H. A biodegradable fibrin scaffold for mesenchymal stem cell transplantation. Biomaterials. 2003;24(14):2497-2502.

3. Sell SA, Wolfe PS, Garg K, McCool JM, Rodriguez IA, Bowlin GL. The use of natural polymers in tissue engineering: a focus on electrospun extracellular matrix analogues. Polymers. 2010;2(4):522-553.

4. Meinhart J, Fussenegger M, Höbling W. Stabilization of fibrinchondrocyte constructs for cartilage reconstruction. Ann Plast Surg. 1999;42(6):673-678.

5. Sahni A, Francis CW. Vascular endothelial growth factor binds to fibrinogen and fibrin and stimulates endothelial cell proliferation. Blood. 2000;96(12):3772-3778.

6. Park KH, Kim H, Moon S, Na K. Bone morphogenic protein-2 (BMP-2) loaded nanoparticles mixed with human mesenchymal stem cell in fibrin hydrogel for bone tissue engineering. J Biosci Bioeng. 2009;108(6): 530-537.

7. Kalbermatten DF, Kingham PJ, Mahay D, et al. Fibrin matrix for suspension of regenerative cells in an artificial nerve conduit. $J$ Plast Reconstr Aesthet Surg. 2008;61(6):669-675.
8. Gorodetsky R, Clark RA, An J, et al. Fibrin microbeads (FMB) as biodegradable carriers for culturing cells and for accelerating wound healing. J Invest Dermatol. 1999;112(6):866-872.

9. Rajangam T, Paik HJ, An SSA. Development of fibrinogen microspheres as a biodegradable carrier for tissue engineering. BioChip J. 2011;5(2): $175-183$.

10. Rajangam T, Paik H-j, An S. Fabricating fibrinogen microfibers with aligned nanostructure, as biodegradable threads for tissue engineering. Bull Korean Chem Soc. 2012;33(6):2075-2078.

11. Swartz DD, Russell JA, Andreadis ST. Engineering of fibrin-based functional and implantable small-diameter blood vessels. Am J Physiol Heart Circ Physiol. 2005;288(3):H1451-H1460.

12. Rejinold NS, Muthunarayanan M, Deepa N, Chennazhi KP, Nair SV, Jayakumar R. Development of novel fibrinogen nanoparticles by twostep co-acervation method. Int J Biol Macromol. 2010;47(1):37-43.

13. Wnek GE, Carr ME, Simpson DG, Bowlin GL. Electrospinning of nanofiber fibrinogen structures. Nano Lett. 2002;3(2):213-216.

14. Rowe SL, Lee S, Stegemann JP. Influence of thrombin concentration on the mechanical and morphological properties of cell-seeded fibrin hydrogels. Acta Biomater. 2007;3(1):59-67.

15. Mosesson MW, Siebenlist KR, Meh DA. The structure and biological features of fibrinogen and fibrin. Ann N Y Acad Sci. 2001;936:11-30.

16. Rybarczyk BJ, Lawrence SO, Simpson-Haidaris PJ. Matrix-fibrinogen enhances wound closure by increasing both cell proliferation and migration. Blood. 2003;102(12):4035-4043.

17. Drew AF, Liu H, Davidson JM, Daugherty CC, Degen JL. Wound-healing defects in mice lacking fibrinogen. Blood. 2001;97(12):3691-3698.

18. Gailit J, Clarke C, Newman D, Tonnesen MG, Mosesson MW, Clark RA. Human fibroblasts bind directly to fibrinogen at RGD sites through integrin alpha(v) beta3. Exp Cell Res. 1997;232(1):118-126.

19. Sahni A, Odrljin T, Francis CW. Binding of basic fibroblast growth factor to fibrinogen and fibrin. J Biol Chem. 1998;273(13):7554-7559.

20. Janmey PA, Winer JP, Weisel JW. Fibrin gels and their clinical and bioengineering applications. J R Soc Interface. 2009;6(30):1-10.

21. Stegemann JP, Kaszuba SN, Rowe SL. Review: advances in vascular tissue engineering using protein-based biomaterials. Tissue Eng. 2007;13(11):2601-2613.

22. Ehrbar M, Metters A, Zammaretti P, Hubbell JA, Zisch AH. Endothelial cell proliferation and progenitor maturation by fibrin-bound VEGF variants with differential susceptibilities to local cellular activity. J Control Release. 2005;101(1-3):93-109.

23. Breen A, O'Brien T, Pandit A. Fibrin as a delivery system for therapeutic drugs and biomolecules. Tissue Eng Part B Rev. 2009;15(2):201-214.

24. Bhang SH, Jeon O, Choi CY, Kwon YH, Kim BS. Controlled release of nerve growth factor from fibrin gel. J Biomed Mater Res A. 2007;80(4): 998-1002.

25. LeeTC, Ho JT, Hung KS, Chen WF, ChungYH, Yang YL. Bone morphogenetic protein gene therapy using a fibrin scaffold for a rabbit spinal-fusion experiment. Neurosurgery. 2006;58(2):373-380; discussion 373-380.

26. Petratos PB, Felsen D, Trierweiler G, Pratt B, McPherson JM, Poppas DP. Transforming growth factor-beta2 (TGF-beta2) reverses the inhibitory effects of fibrin sealant on cutaneous wound repair in the pig. Wound Repair Regen. 2002;10(4):252-258.

27. Yang HS, Bhang SH, Hwang JW, Kim DI, Kim BS. Delivery of basic fibroblast growth factor using heparin-conjugated fibrin for therapeutic angiogenesis. Tissue Eng Part A. 2010;16(6):2113-2119.

28. Clark RA, Lanigan JM, DellaPelle P, Manseau E, Dvorak HF, Colvin RB. Fibronectin and fibrin provide a provisional matrix for epidermal cell migration during wound reepithelialization. J Investig Dermatol. 1982;79(5):264-269.

29. Hartmann A, Quist J, Hamm H, Bröcker EB, Friedl P. Transplantation of autologous keratinocyte suspension in fibrin matrix to chronic venous leg ulcers: improved long-term healing after removal of the fibrin carrier. Dermatol Surg. 2008;34(7):922-929.

30. Jay SM, Saltzman WM. Controlled delivery of VEGF via modulation of alginate microparticle ionic crosslinking. J Control Release. 2009;134(1):26-34. 
31. Hiemstra C, Zhong Z, van Steenbergen MJ, Hennink WE, Feijen J. Release of model proteins and basic fibroblast growth factor from in situ forming degradable dextran hydrogels. J Control Release. 2007;122(1): $71-78$.

32. Cai S, Liu Y, Zheng Shu X, Prestwich GD. Injectable glycosaminoglycan hydrogels for controlled release of human basic fibroblast growth factor. Biomaterials. 2005;26(30):6054-6067.

33. Vrana NE, Liu Y, McGuinness GB, Cahill PA. Characterization of poly(vinyl alcohol)/chitosan hydrogels as vascular tissue engineering scaffolds. Macromol Symp. 2008;269(1):106-110.

34. Zhong Y, Zhang L, Ding AG, et al. Rescue of SCID murine ischemic hindlimbs with $\mathrm{pH}$-modified rhbFGF/poly(DL-lactic-co-glycolic acid) implants. J Control Release. 2007;122(3):331-337.

35. Chung YI, Kim SK, Lee YK, et al. Efficient revascularization by VEGF administration via heparin-functionalized nanoparticle-fibrin complex. J Control Release. 2010;143(3):282-289.

36. Miyazaki S, Hashiguchi N, Sugiyama M, Takada M, Morimoto Y. Fibrinogen microspheres as novel drug delivery systems for antitumor drugs. Chem Pharm Bull (Tokyo). 1986;34(3):1370-1375.

37. Ho HO, Hsiao CC, Chen CY, Sokoloski TD, Sheu MT. Fibrin-based drug delivery systems III: The evaluation of the release of macromolecules from microbeads. J Control Release. 1995;34(1):65-70.

38. Levi M, Friederich PW, Middleton S, et al. Fibrinogen-coated albumin microcapsules reduce bleeding in severely thrombocytopenic rabbits. Nat Med. 1999;5(1):107-111.

39. Miyazaki S, Hashiguchi N, Hou WM, Yokouchi C, Takada M. Preparation and evaluation in vitro and in vivo of fibrinogen microspheres containing adriamycin. Chem Pharm Bull (Tokyo). 1986;34(8): 3384-3393.

40. Kulkarni MM, Greiser U, O'Brien T, Pandit A. A temporal gene delivery system based on fibrin microspheres. Mol Pharm. 2011;8(2): 439-446.

41. Ho HO, Hsiao CC, Chen CY, Sokoloski TD, Sheu MT. Fibrin-based drug delivery systems. II. The preparation and characterization of microbeads. Drug Dev Ind Pharm. 1994;20(4):535-546.

42. Rejinold NS, Muthunarayanan M, Chennazhi KP, Nair SV, Jayakumar R. 5-fluorouracil loaded fibrinogen nanoparticles for cancer drug delivery applications. Intl J Biol Macromol. 2011;48(1):98-105.

43. McManus MC, Boland ED, Koo HP, et al. Mechanical properties of electrospun fibrinogen structures. Acta Biomater. 2006;2(1):19-28.

44. McManus MC, Boland ED, Simpson DG, Barnes CP, Bowlin GL. Electrospun fibrinogen: feasibility as a tissue engineering scaffold in a rat cell culture model. J Biomed Mater Res A. 2007;81(2):299-309.

45. Sell SA, Francis MP, Garg K, McClure MJ, Simpson DG, Bowlin GL. Cross-linking methods of electrospun fibrinogen scaffolds for tissue engineering applications. Biomed Mater. 2008;3(4):045001.

46. Carlisle CR, Coulais C, Namboothiry M, Carroll DL, Hantgan RR, Guthold M. The mechanical properties of individual, electrospun fibrinogen fibers. Biomaterials. 2009;30(6):1205-1213.

47. McManus M, Boland E, Sell S, et al. Electrospun nanofibre fibrinogen for urinary tract tissue reconstruction. Biomed Mater. 2007;2(4): $257-262$.

48. McManus MC, Sell SA, Bowen WC, Koo HP, Simpson DG, Bowlin GL. Electrospun fibrinogen-polydioxanone composite matrix: potential for in situ urologic tissue engineering. J Eng Fiber Fabr. 2008;3(2): $12-21$.

49. Ng R, Zang R, Yang KK, Liu N, Yang ST. Three-dimensional fibrous scaffolds with microstructures and nanotextures for tissue engineering. RSC Adv. 2012;2(27):10110-10124.

50. Pittenger MF, Mackay AM, Beck SC, et al. Multilineage potential of adult human mesenchymal stem cells. Science. 1999;284(5411):143-147.

51. Rajangam T, An SS. Improved fibronectin-immobilized fibrinogen microthreads for the attachment and proliferation of fibroblasts. Int $J$ Nanomedicine. 2013;8:1037-1049.

52. Currie LJ, Sharpe JR, Martin R. The use of fibrin glue in skin grafts and tissue-engineered skin replacements: a review. Plast Reconstr Surg. 2001;108(6):1713-1726.
53. Matras H. Fibrin seal: The state of the art. J Oral Maxillofac Surg. 1985;43(8):605-611.

54. Saltz R, Sierra D, Feldman D, Saltz MB, Dimick A, Vasconez LO. Experimental and clinical applications of fibrin glue. Plast Reconstr Surg. 1991;88(6):1005-1015; discussion 1016-1017.

55. Blombäck B, Bark N. Fibrinopeptides and fibrin gel structure. Biophys Chem. 2004;112(2-3):147-151.

56. Blombäck B, Carlsson K, Hessel B, Liljeborg A, Procyk R, Åslund N. Native fibrin gel networks observed by $3 \mathrm{D}$ microscopy, permeation and turbidity. Biochim Biophys Acta. 1989;997(1-2):96-110.

57. Kubota K, Kogure H, Masuda Y, et al. Gelation dynamics and gel structure of fibrinogen. Colloids Surf B Biointerfaces. 2004;38(3-4): 103-109.

58. Sha'ban M, Kim SH, Idrus RB, Khang G. Fibrin and poly(lactic-coglycolic acid) hybrid scaffold promotes early chondrogenesis of articular chondrocytes: an in vitro study. J Orthop Surg Res. 2008;3:17.

59. Mol A, van Lieshout MI, Dam-de Veen CG, et al. Fibrin as a cell carrier in cardiovascular tissue engineering applications. Biomaterials. 2005;26(16):3113-3121.

60. Almany L, Seliktar D. Biosynthetic hydrogel scaffolds made from fibrinogen and polyethylene glycol for 3D cell cultures. Biomaterials. 2005;26(15):2467-2477.

61. Zhao H, Ma L, Gong Y, Gao C, Shen J. A polylactide/fibrin gel composite scaffold for cartilage tissue engineering: fabrication and an in vitro evaluation. J Mater Sci Mater Med. 2009;20(1):135-143.

62. Lei Y, Rahim M, Ng Q, Segura T. Hyaluronic acid and fibrin hydrogels with concentrated DNA/PEI polyplexes for local gene delivery. $J$ Control Release. 2011;153(3):255-261.

63. Shachaf Y, Gonen-Wadmany M, Seliktar D. The biocompatibility of PluronicF127 fibrinogen-based hydrogels. Biomaterials. 2010;31(10): 2836-2847.

64. Ikari Y, Fujikawa K, Yee KO, Schwartz SM. Alpha(1)-proteinase inhibitor, alpha(1)-antichymotrypsin, or alpha(2)-macroglobulin is required for vascular smooth muscle cell spreading in three-dimensional fibrin gel. J Biol Chem. 2000;275(17):12799-12805.

65. Ye Q, Zünd G, Benedikt $P$, et al. Fibrin gel as a three dimensional matrix in cardiovascular tissue engineering. Eur J Cardiothorac Surg. 2000;17(5):587-591.

66. Haugh MG, Thorpe SD, Vinardell T, Buckley CT, Kelly DJ. The application of plastic compression to modulate fibrin hydrogel mechanical properties. J Mech Behav Biomed Mater. 2012;16:66-72.

67. Kim SJ, Jang DH, Park WH, Min BM. Fabrication and characterization of 3-dimensional PLGA nanofiber/microfiber composite scaffolds. Polymer. 2010;51(6):1320-1327.

68. Marimuthu M, Kim S. Survey of the state of the art in biomaterials, cells, genes and proteins integrated into micro- and nanoscaffolds for tissue regeneration. Current Nanoscience. 2009;5(2):189-203.

69. Takei A, Tashiro Y, Nakashima Y, Sueishi K. Effects of fibrin on the angiogenesis in vitro of bovine endothelial cells in collagen gel. In Vitro Cell Dev Biol Anim. 1995;31(6):467-472.

70. Bootle-Wilbraham CA, Tazzyman S, Thompson WD, Stirk CM, Lewis CE. Fibrin fragment $\mathrm{E}$ stimulates the proliferation, migration and differentiation of human microvascular endothelial cells in vitro. Angiogenesis. 2001;4(4):269-275.

71. Herrick S, Blanc-Brude O, Gray A, Laurent G. Fibrinogen. Int J Biochem Cell Biol. 1999;31(7):741-746.

72. Oss-Ronen L, Seliktar D. Polymer-conjugated albumin and fibrinogen composite hydrogels as cell scaffolds designed for affinity-based drug delivery. Acta Biomater. 2011;7(1):163-170.

73. Le Nihouannen D, Saffarzadeh A, Aguado E, et al. Osteogenic properties of calcium phosphate ceramics and fibrin glue based composites. J Mater Sci Mater Med. 2007;18(2):225-235.

74. Frisman I, Seliktar D, Bianco-Peled H. Nanostructuring of PEG-fibrinogen polymeric scaffolds. Acta Biomater. 2010;6(7):2518-2524.

75. Van Lieshout M, Peters G, Rutten M, Baaijens F. A knitted, fibrincovered polycaprolactone scaffold for tissue engineering of the aortic valve. Tissue Eng. 2006;12(3):481-487. 
76. Lee CR, Grad S, Gorna K, Gogolewski S, Goessl A, Alini M. Fibrinpolyurethane composites for articular cartilage tissue engineering: a preliminary analysis. Tissue Eng. 2005;11(9-10):1562-1573.

77. De Laporte L, Yan AL, Shea LD. Local gene delivery from ECM-coated poly(lactide-co-glycolide) multiple channel bridges after spinal cord injury. Biomaterials. 2009;30(12):2361-2368.

78. Lei Y, Huang S, Sharif-Kashani P, Chen Y, Kavehpour P, Segura T. Incorporation of active DNA/cationic polymer polyplexes into hydrogel scaffolds. Biomaterials. 2010;31(34):9106-9116.

79. Osathanon T, Linnes ML, Rajachar RM, Ratner BD, Somerman MJ, Giachelli CM. Microporous nanofibrous fibrin-based scaffolds for bone tissue engineering. Biomaterials. 2008;29(30):4091-4099.

80. Pankajakshan D, Philipose LP, Palakkal M, Krishnan K, Krishnan LK. Development of a fibrin composite-coated poly(epsilon-caprolactone) scaffold for potential vascular tissue engineering applications. J Biomed Mater Res B Appl Biomater. 2008;87(2):570-579.

81. Thein-Han WW, Saikhun J, Pholpramoo C, Misra RDK, Kitiyanant Y. Chitosan-gelatin scaffolds for tissue engineering: physico-chemical properties and biological response of buffalo embryonic stem cells and transfectant of GFP-buffalo embryonic stem cells. Acta Biomater. 2009;5(9):3453-3466.

82. Noorjahan SE, Sastry TP. An in vivo study of hydrogels based on physiologically clotted fibrin-gelatin composites as wound-dressing materials. J Biomed Mater Res B Appl Biomater. 2004;71(2):305-312.

83. Natarajan N, Shashirekha V, Noorjahan SE, Rameshkumar M, Rose C, Sastry TP. Fibrin-chitosan-gelatin composite film: preparation and characterization. Journal of Macromolecular Science, Part A: Pure and Applied Chemistry. 2005;42(7):945-953.

84. Xu W, Wang X, Yan Y, et al. Rapid prototyping three-dimensional cell/ gelatin/fibrinogen constructs for medical regeneration. J Bioact Compat Polym. 2007;22(4):363-377.

85. Erdogan D, van Gulik TM. Evolution of fibrinogen-coated collagen patch for use as a topical hemostatic agent. J Biomed Mater Res B Appl Biomater. 2008;85(1):272-278.

86. Han CM, Zhang LP, Sun JZ, Shi HF, Zhou J, Gao CY. Application of collagen-chitosan/fibrin glue asymmetric scaffolds in skin tissue engineering. J Zhejiang Univ Sci B. 2010;11(7):524-530.

87. Lorusso R, De Cicco G, Vizzardi E, Gelsomino S. Human fibrinogen/ thrombin-coated collagen patch to control intraoperative severe pulmonary hemorrhage and air leakage after correction of a ruptured thoracic aortic aneurysm. Ann Thorac Surg. 2011;91(3):917-919.

88. Chen Z, Wang L, Stegemann JP. Phase-separated chitosan-fibrin microbeads for cell delivery. J Microencapsul. 2011;28(5):344-352.

89. Cummings CL, Gawlitta D, Nerem RM, Stegemann JP. Properties of engineered vascular constructs made from collagen, fibrin, and collagenfibrin mixtures. Biomaterials. 2004;25(17):3699-3706.

90. Zhou W, Zhao M, Zhao Y, Mou Y. A fibrin gel loaded with chitosan nanoparticles for local delivery of rhEGF: preparation and in vitro release studies. J Mater Sci Mater Med. 2011;22(5):1221-1230.

91. Park SH, Choi BH, Park SR, Min BH. Chondrogenesis of rabbit mesenchymal stem cells in fibrin/hyaluronan composite scaffold in vitro. Tissue Eng Part A. 2011;17(9-10):1277-1286.

92. Perka C, Schultz O, Lindenhayn K, et al. Joint cartilage repair with transplantation of embryonic chondrocytes embedded in collagen-fibrin matrices. Clin Exp Rheumatol. 2000;18(1):13-22.

93. Park SH, Park SR, Chung SI, Pai KS, Min BH. Tissue-engineered cartilage using fibrin/hyaluronan composite gel and its in vivo implantation. Artif Organs. 2005;29(10):838-845.

94. Briganti E, Spiller D, Mirtelli C, et al. A composite fibrin-based scaffold for controlled delivery of bioactive pro-angiogenetic growth factors. J Control Release. 2010;142(1):14-21.

95. Filová E, Jelinek F, Handl M, et al. Novel composite hyaluronan/type I collagen/fibrin scaffold enhances repair of osteochondral defect in rabbit knee. J Biomed Mater Res B Appl Biomater. 2008;87(2):415-424.

96. Venkatraman S, Boey F, Lao LL. Implanted cardiovascular polymers: Natural, synthetic and bio-inspired. Prog Polym Sci. 2008;33(9): 853-874.
97. Marder VJ. Identification and purification of fibrinogen degradation products produced by plasmin: considerations on the structure of fibrinogen. Scand J Haematol Suppl. 1971;13:21-36.

98. Ständker L, Sillard R, Bensch KW, et al. In vivo degradation of human fibrinogen $A \alpha$ : detection of cleavage sites and release of antithrombotic peptides. Biochem Biophys Res Commun. 1995;215(3):896-902.

99. Mihályí E. Cross-linking of bovine fibrinogen with formaldehyde. Acta Chem Scand. 1963;17 Suppl:S277-S281.

100. Furlan M, Beck EA. Cross-linking of human fibrinogen with glutaraldehyde and tetranitromethane. Thromb Res. 1975;7(6):827-838.

101. Olde Damink LH, Dijkstra PJ, van Luyn MJ, van Wachem PB, Nieuwenhuis P, Feijen J. Cross-linking of dermal sheep collagen using a water-soluble carbodiimide. Biomaterials. 1996;17(8):765-773.

102. Sung HW, Chang WH, Ma CY, Lee MH. Crosslinking of biological tissues using genipin and/or carbodiimide. J Biomed Mater Res A. 2003;64(3):427-438.

103. Jayakrishnan A, Jameela SR. Glutaraldehyde as a fixative in bioprostheses and drug delivery matrices. Biomaterials. 1996;17(5): $471-484$

104. Dare EV, Griffith M, Poitras P, et al. Genipin cross-linked fibrin hydrogels for in vitro human articular cartilage tissue-engineered regeneration. Cells Tissues Organs. 2009;190(6):313-325.

105. Fussenegger M, Meinhart J, Höbling W, Kullich W, Funk S, Bernatzky G. Stabilized autologous fibrin-chondrocyte constructs for cartilage repair in vivo. Ann Plast Surg. 2003;51(5):493-498.

106. Eyrich D, Brandl F, Appel B, et al. Long-term stable fibrin gels for cartilage engineering. Biomaterials. 2007;28(1):55-65.

107. Osada K, Christie RJ, Kataoka K. Polymeric micelles from poly(ethylene glycol)-poly(amino acid) block copolymer for drug and gene delivery. J R Soc Interface. 2009;6 Suppl 3:S325-S339.

108. Costantini V, Zacharski LR. The role of fibrin in tumor metastasis. Cancer Metastasis Rev 1992;11(3):283-290.

109. Einhaus CM, Retzinger AC, Perrotta AO, et al. Fibrinogen-coated droplets of olive oil for delivery of docetaxel to a fibrin(ogen)rich ascites form of a murine mammary tumor. Clin Cancer Res. 2004;10(20):7001-7010.

110. Rejinold NS, Muthunarayanan M, Chennazhi KP, Nair SV, Jayakumar R. Curcumin loaded fibrinogen nanoparticles for cancer drug delivery. J Biomed Nanotechnol. 2011;7(4):521-534.

111. Asahara T, Bauters C, Zheng LP, et al. Synergistic effect of vascular endothelial growth factor and basic fibroblast growth factor on angiogenesis in vivo. Circulation. 1995;92(Suppl 9):S365-S371.

112. Hughes GC, Biswas SS, Yin B, et al. Therapeutic angiogenesis in chronically ischemic porcine myocardium: comparative effects of bFGF and VEGF. Ann Thorac Surg. 2004;77(3):812-818.

113. Mimura T, Imai S, Kubo M, et al. A novel exogenous concentrationgradient collagen scaffold augments full-thickness articular cartilage repair. Osteoarthritis Cartilage. 2008;16(9):1083-1091.

114. Okumura M, Okuda T, Nakamura T, Yajima M. Acceleration of wound healing in diabetic mice by basic fibroblast growth factor. Biol Pharm Bull. 1996;19(4):530-535.

115. Wilcke I, Lohmeyer JA, Liu S, et al. VEGF(165) and bFGF proteinbased therapy in a slow release system to improve angiogenesis in a bioartificial dermal substitute in vitro and in vivo. Langenbecks Arch Surg. 2007;392(3):305-314.

116. Hasegawa T, Kimura A, Miyataka M, Inagaki M, Ishikawa K. Basic fibroblast growth factor increases regional myocardial blood flow and salvages myocardium in the infarct border zone in a rabbit model of acute myocardial infarction. Angiology. 1999;50(6):487-495.

117. Losordo DW, Vale PR, Hendel RC, et al. Phase 1/2 placebo-controlled, double-blind, dose-escalating trial of myocardial vascular endothelial growth factor 2 gene transfer by catheter delivery in patients with chronic myocardial ischemia. Circulation. 2002;105(17): 2012-2018.

118. Gibran NS, Isik FF, Heimbach DM, Gordon D. Basic fibroblast growth factor in the early human burn wound. J Surg Res. 1994;56(3): 226-234 
119. Robson MC, Phillips LG, Lawrence WT, et al. The safety and effect of topically applied recombinant basic fibroblast growth factor on the healing of chronic pressure sores. Ann Surg. 1992;216(4):401-406; discussion 406-408.

120. Lee KY, Peters MC, Mooney DJ. Comparison of vascular endothelial growth factor and basic fibroblast growth factor on angiogenesis in SCID mice. J Control Release. 2003;87(1-3):49-56.

121. Sakiyama-Elbert SE, Hubbell JA. Controlled release of nerve growth factor from a heparin-containing fibrin-based cell ingrowth matrix. J Control Release. 2000;69(1):149-158.

122. Taylor SJ, Rosenzweig ES, McDonald JW 3rd, Sakiyama-Elbert SE. Delivery of neurotrophin-3 from fibrin enhances neuronal fiber sprouting after spinal cord injury. J Control Release. 2006;113(3): 226-235.

123. Davies AM. The role of neurotrophins in the developing nervous system. J Neurobiol. 1994;25(11):1334-1348.

124. Taylor SJ, McDonald JW 3rd, Sakiyama-Elbert SE. Controlled release of neurotrophin-3 from fibrin gels for spinal cord injury. J Control Release. 2004;98(2):281-294.

125. Willerth SM, Sakiyama-Elbert SE. Approaches to neural tissue engineering using scaffolds for drug delivery. Adv Drug Deliv Rev. 2007;59(4-5):325-338.

126. Romero MI, Rangappa N, Garry MG, Smith GM. Functional regeneration of chronically injured sensory afferents into adult spinal cord after neurotrophin gene therapy. J Neurosci. 2001;21(21):8408-8416.

127. Grill R, Murai K, Blesch A, Gage FH, Tuszynski MH. Cellular delivery of neurotrophin-3 promotes corticospinal axonal growth and partial functional recovery after spinal cord injury. J Neurosci. 1997;17(14): 5560-5572.

128. Schnell L, Schneider R, Kolbeck R, Barde YA, Schwab ME. Neurotrophin-3 enhances sprouting of corticospinal tract during development and after adult spinal cord lesion. Nature. 1994;367(6459): 170-173.

129. Sakiyama SE, Schense JC, Hubbell JA. Incorporation of heparinbinding peptides into fibrin gels enhances neurite extension: an example of designer matrices in tissue engineering. FASEB J. 1999;13(15): 2214-2224.

130. Sakiyama-Elbert SE, Hubbell JA. Development of fibrin derivatives for controlled release of heparin-binding growth factors. J Control Release. 2000;65(3):389-402.

131. Bennet D, Kim S. Implantable microdevice for peripheral nerve regeneration: materials and fabrications. J Mater Sci. 2011;46(14): 4723-4740.

132. Taylor SJ, Sakiyama-Elbert SE. Effect of controlled delivery of neurotrophin-3 from fibrin on spinal cord injury in a long term model. J Control Release. 2006;116(2):204-210.

133. Sakiyama-Elbert SE, Panitch A, Hubbell JA. Development of growth factor fusion proteins for cell-triggered drug delivery. FASEB J. 2001;15(7):1300-1302.

134. Iwaya K, Mizoi K, Tessler A, Itoh Y. Neurotrophic agents in fibrin glue mediate adult dorsal root regeneration into spinal cord. Neurosurgery. 1999;44(3):589-595; discussion 595-596.

135. Tohill M, Terenghi G. Stem-cell plasticity and therapy for injuries of the peripheral nervous system. Biotechnol Appl Biochem. 2004;40(Pt 1): $17-24$.

136. Caddick J, Kingham PJ, Gardiner NJ, Wiberg M, Terenghi G. Phenotypic and functional characteristics of mesenchymal stem cells differentiated along a Schwann cell lineage. Glia. 2006;54(8): 840-849.

137. Siegel GJ, Chauhan NB. Neurotrophic factors in Alzheimer's and Parkinson's disease brain. Brain Res Rev. 2000;33(2-3):199-227.

138. Williams LR, Longo FM, Powell HC, Lundborg G, Varon S. Spatial-temporal progress of peripheral nerve regeneration within a silicone chamber: parameters for a bioassay. J Comp Neurol. 1983;218(4): 460-470.

139. Buckwalter JA, Mankin HJ. Articular cartilage: tissue design and chondrocyte-matrix interactions. Instr Course Lect. 1998;47:477-486.
140. Malafaya P, Silva GA, Baran ET, Reis RL. Drug delivery therapies I - General trends and its importance on bone tissue engineering applications. Curr Opin Solid State Mater Sci. 2002;6(4): 283-295.

141. Lee K, Silva EA, Mooney DJ. Growth factor delivery-based tissue engineering: general approaches and a review of recent developments. $J R$ Soc Interface. 2011;8(55):153-170.

142. Smoljanović T, Grgurević L, Jelić M, et al. Regeneration of the skeleton by recombinant human bone morphogenetic proteins. Coll Antropol. 2007;31(3):923-932.

143. Centrella M, Massagué J, Canalis E. Human platelet-derived transforming growth factor-beta stimulates parameters of bone growth in fetal rat calvariae. Endocrinology. 1986;119(5):2306-2312.

144. Cuevas P, Burgos J, Baird A. Basic fibroblast growth factor (FGF) promotes cartilage repair in vivo. Biochem Biophys Res Commun. 1988;156(2):611-618.

145. Noda M, Camilliere JJ. In vivo stimulation of bone formation by transforming growth factor-beta. Endocrinology. 1989;124(6): 2991-2994.

146. Saraf A, Mikos AG. Gene delivery strategies for cartilage tissue engineering. Adv Drug Deliv Rev. 2006;58(4):592-603.

147. Kundu B, Khare SK, Singh G. Role of polypeptides in the treatment and diagnosis of osteoporosis. Peptides. 1999;20(4):523-537.

148. Patel S, Rodriguez-Merchan EC, Haddad FS. The use of fibrin glue in surgery of the knee. J Bone Joint Surg Br. 2010;92(10):1325-1331.

149. Ishimura M, Ohgushi H, Habata T, Tamai S, Fujisawa Y. Arthroscopic meniscal repair using fibrin glue. Part I: Experimental study. Arthroscopy. 1997;13(5):551-557.

150. Schmoekel HG, Weber FE, Schense JC, Grätz KW, Schawalder P, Hubbell JA. Bone repair with a form of BMP-2 engineered for incorporation into fibrin cell ingrowth matrices. Biotechnol Bioeng. 2005;89(3):253-262.

151. Han D, Liu W, Ao Q, Wang G. Optimal delivery systems for bone morphogenetic proteins in orthopedic applications should model initial tissue repair structures by using a heparin-incorporated fibrin-fibronectin matrix. Med Hypotheses. 2008;71(3): 374-378.

152. Kang SW, Kim JS, Park KS, et al. Surface modification with fibrin/ hyaluronic acid hydrogel on solid-free form-based scaffolds followed by BMP-2 loading to enhance bone regeneration. Bone. 2011;48(2): 298-306.

153. Roeddecker K, Nagelschmidt M, Koebke J, Guensche K. Meniscal healing: a histological study in rabbits. Knee Surg Sports Traumatol Arthrosc. 1993;1(1):28-33.

154. Izuta Y, Ochi M, Adachi N, Deie M, Yamasaki T, Shinomiya R. Meniscal repair using bone marrow-derived mesenchymal stem cells: experimental study using green fluorescent protein transgenic rats. Knee. 2005;12(3):217-223.

155. Hashimoto J, Kurosaka M, Yoshiya S, Hirohata K. Meniscal repair using fibrin sealant and endothelial cell growth factor. An experimental study in dogs. Am J Sports Med. 1992;20(5):537-541.

156. Scotti C, Pozzi A, Mangiavini L, et al. Healing of meniscal tissue by cellular fibrin glue: an in vivo study. Knee Surg Sports Traumatol Arthrosc. 2009;17(6):645-651.

157. Yamada Y, Boo JS, Ozawa R, et al. Bone regeneration following injection of mesenchymal stem cells and fibrin glue with a biodegradable scaffold. J Craniomaxillofac Surg. 2003;31(1):27-33.

158. Gurevich O, Vexler A, Marx G, et al. Fibrin microbeads for isolating and growing bone marrow-derived progenitor cells capable of forming bone tissue. Tissue Eng. 2002;8(4):661-672.

159. Isogai N, Landis WJ, Mori R, et al. Experimental use of fibrin glue to induce site-directed osteogenesis from cultured periosteal cells. Plast Reconstr Surg. 2000;105(3):953-963.

160. Albrektsson T, Bach A, Edshage S, Jönsson A. Fibrin adhesive system (FAS) influence on bone healing rate: a microradiographical evaluation using the bone growth chamber. Acta Orthop Scand. 1982;53(5):757-763. 
161. Rousou J, Levitsky S, Gonzalez-Lavin L, et al. Randomized clinical trial of fibrin sealant in patients undergoing resternotomy or reoperation after cardiac operations. A multicenter study. JThorac Cardiovasc Surg. 1989;97(2):194-203.

162. Abiraman S, Varma HK, Umashankar PR, John A. Fibrin glue as an osteoinductive protein in a mouse model. Biomaterials. 2002;23(14): 3023-3031

163. Wittkampf AR. Fibrin glue as cement for HA-granules. J Craniomaxillofac Surg. 1989;17(4):179-181.

164. Thompson JA, Anderson KD, DiPietro JM, et al. Site-directed neovessel formation in vivo. Science. 1988;241(4871):1349-1352.

165. Asahara T, Bauters C, Pastore C, et al. Local delivery of vascular endothelial growth factor accelerates reendothelialization and attenuates intimal hyperplasia in balloon-injured rat carotid artery. Circulation. 1995;91(11):2793-2801.

166. Asahara T, Chen D, Tsurumi Y, et al. Accelerated restitution of endothelial integrity and endothelium-dependent function after phVEGF165 gene transfer. Circulation. 1996;94(12):3291-3302.

167. Van Belle E, Tio FO, Couffinhal T, Maillard L, Passeri J, Isner JM. Stent endothelialization. Time course, impact of local catheter delivery, feasibility of recombinant protein administration, and response to cytokine expedition. Circulation. 1997;95(2):438-448.

168. DeBlois C, Côté MF, Doillon CJ. Heparin-fibroblast growth factorfibrin complex: in vitro and in vivo applications to collagen-based materials. Biomaterials. 1994;15(9):665-672.

169. Brown KJ, Maynes SF, Bezos A, Maguire DJ, Ford MD, Parish CR. A novel in vitro assay for human angiogenesis. Lab Invest. 1996;75(4): 539-555.

170. Zisch AH, Lutolf MP, Hubbell JA. Biopolymeric delivery matrices for angiogenic growth factors. Cardiovasc Pathol. 2003;12(6):295-310.

171. Wu X, Ma J, Han JD, Wang N, Chen YG. Distinct regulation of gene expression in human endothelial cells by TGF-beta and its receptors. Microvasc Res. 2006;71(1):12-19.

172. Fasol R, Schumacher B, Schlaudraff K, Hauenstein KH, Seitelberger R. Experimental use of a modified fibrin glue to induce site-directed angiogenesis from the aorta to the heart. J Thorac Cardiovasc Surg. 1994;107(6):1432-1439.

173. Greisler HP, Cziperle DJ, Kim DU, et al. Enhanced endothelialization of expanded polytetrafluoroethylene grafts by fibroblast growth factor type 1 pretreatment. Surgery. 1992;112(2):244-254; discussion 254-255.

174. Zisch AH, Schenk U, Schense JC, Sakiyama-Elbert SE, Hubbell JA. Covalently conjugated VEGF - fibrin matrices for endothelialization. J Control Release. 2001;72(1-3):101-113.

175. Shireman PK, Greisler HP. Mitogenicity and release of vascular endothelial growth factor with and without heparin from fibrin glue. J Vasc Surg. 2000;31(5):936-943.

176. Wong C, Inman E, Spaethe R, Helgerson S. Fibrin-based biomaterials to deliver human growth factors. Thromb Haemost. 2003;89(3): 573-582.

177. Arkudas A, Tjiawi J, Bleiziffer O, et al. Fibrin gel-immobilized VEGF and bFGF efficiently stimulate angiogenesis in the AV loop model. Mol Med. 2007;13(9-10):480-487.

178. DiMuzio P, Tulenko T. Tissue engineering applications to vascular bypass graft development: the use of adipose-derived stem cells. J Vasc Surg. 2007;45 Suppl A:A99-A103.

179. Charwat S, Gyöngyösi M, Lang I, et al. Role of adult bone marrow stem cells in the repair of ischemic myocardium: current state of the art. Exp Hematol. 2008;36(6):672-680.

180. Zhang G, Suggs LJ. Matrices and scaffolds for drug delivery in vascular tissue engineering. Adv Drug Deliv Rev. 2007;59(4-5):360-373.

181. Jones JI, Prevette T, Gockerman A, Clemmons DR. Ligand occupancy of the alpha-V-beta3 integrin is necessary for smooth muscle cells to migrate in response to insulin-like growth factor. Proc Natl Acad Sci US A. 1996;93(6):2482-2487.
182. Christman KL, Fok HH, Sievers RE, Fang Q, Lee RJ. Fibrin glue alone and skeletal myoblasts in a fibrin scaffold preserve cardiac function after myocardial infarction. Tissue Eng. 2004;10(3-4):403-409.

183. Fu XB. Growth factors and skin repair and regeneration. Int J Cosmet Sci. 2005;27(1):40-41.

184. Tsuruma A, Tanaka M, Yamamoto S, Shimomura M. Control of neural stem cell differentiation on honeycomb films. Colloids Surf A Physicochem Eng Asp. 2008;313-314:536-540.

185. Chen WY, Rogers AA, Lydon MJ. Characterization of biologic properties of wound fluid collected during early stages of wound healing. J Invest Dermatol. 1992;99(5):559-564.

186. Aaronson SA, Bottaro DP, Miki T, et al. Keratinocyte growth factor. A fibroblast growth factor family member with unusual target cell specificity. Ann N Y Acad Sci. 1991;638:62-77.

187. Werner S. Keratinocyte growth factor: a unique player in epithelial repair processes. Cytokine Growth Factor Rev. 1998;9(2):153-165.

188. Mogford JE, Tawil B, Jia S, Mustoe TA. Fibrin sealant combined with fibroblasts and platelet-derived growth factor enhance wound healing in excisional wounds. Wound Repair Regen. 2009;17(3):405-410.

189. Geer DJ, Swartz DD, Andreadis ST. Biomimetic delivery of keratinocyte growth factor upon cellular demand for accelerated wound healing in vitro and in vivo. Am J Pathol. 2005;167(6): 1575-1586.

190. Gwak SJ, Kim SS, Sung K, Han J, Choi CY, Kim BS. Synergistic effect of keratinocyte transplantation and epidermal growth factor delivery on epidermal regeneration. Cell Transplant. 2005;14(10):809-817.

191. Kitajima T, Sakuragi M, Hasuda H, Ozu T, Ito Y. A chimeric epidermal growth factor with fibrin affinity promotes repair of injured keratinocyte sheets. Acta Biomater. 2009;5(7):2623-2632.

192. Ali IU, Hynes RO. Effects of LETS glycoprotein on cell motility. Cell. 1978;14(2):439-446.

193. Postlethwaite AE, Keski-Oja J, Balian G, Kang AH. Induction of fibroblast chemotaxis by fibronectin. Localization of the chemotactic region to a 140,000-molecular weight non-gelatin-binding fragment. J Exp Med. 1981;153(2):494-499.

194. Bowersox JC, Sorgente N. Chemotaxis of aortic endothelial cells in response to fibronectin. Cancer Res. 1982;42(7):2547-2551.

195. Remold HG, Shaw JE, David JR. A macrophage surface component related to fibronectin is involved in the response to migration inhibitory factor. Cell Immunol. 1981;58(1):175-187.

196. Bucala R, Spiegel LA, Chesney J, Hogan M, Cerami A. Circulating fibrocytes define a new leukocyte subpopulation that mediates tissue repair. Mol Med. 1994;1(1):71-81.

197. Liu Y, Suwa F, Wang X, et al. Reconstruction of a tissue-engineered skin containing melanocytes. Cell Biol Int. 2007;31(9):985-990.

198. Hartlapp I, Abe R, Saeed RW, et al. Fibrocytes induce an angiogenic phenotype in cultured endothelial cells and promote angiogenesis in vivo. FASEB J. 2001;15(12):2215-2224.

199. Horch RE, Bannasch H, Stark GB. Transplantation of cultured autologous keratinocytes in fibrin sealant biomatrix to resurface chronic wounds. Transplant Proc. 2001;33(1-2):642-644.

200. Yamamoto M, Yanaga H, Nishina H, Watabe S, Mamba K. Fibrin stimulates the proliferation of human keratinocytes through the autocrine mechanism of transforming growth factor-alpha and epidermal growth factor receptor. Tohoku J Exp Med. 2005;207(1): 33-40.

201. Breen AM, Dockery P, O'Brien T, Pandit AS. The use of therapeutic gene eNOS delivered via a fibrin scaffold enhances wound healing in a compromised wound model. Biomaterials. 2008;29(21): 3143-3151.

202. Yamasaki K, Edington HD, McClosky C, et al. Reversal of impaired wound repair in iNOS-deficient mice by topical adenoviral-mediated iNOS gene transfer. J Clin Invest. 1998;101(5):967-971. 


\section{Publish your work in this journal}

The International Journal of Nanomedicine is an international, peerreviewed journal focusing on the application of nanotechnology in diagnostics, therapeutics, and drug delivery systems throughout the biomedical field. This journal is indexed on PubMed Central, MedLine, CAS, SciSearch $\AA$, Current Contents ${ }^{\circledR} /$ Clinical Medicine,
Journal Citation Reports/Science Edition, EMBase, Scopus and the Elsevier Bibliographic databases. The manuscript management system is completely online and includes a very quick and fair peer-review system, which is all easy to use. Visit http://www.dovepress.com/ testimonials.php to read real quotes from published authors.

Submit your manuscript here: http://www.dovepress.com/international-journal-of-nanomedicine-journal 